\title{
EQUIDAD DE GÉNERO EN COSTA RICA: DEL RECONOCIMIENTO A LA REDISTRIBUCIÓN ${ }^{1}$
}

\section{GENDER EQUALITY IN COSTA RICA: FROM RECOGNITION TO REDISTRIBUTION}

\author{
Rafael Arias Ramírez* \\ Rafael Sánchez Meza** \\ Leonardo Sánchez Hernández ${ }^{* * *}$
}

RESUMEN

Para los propósitos de este artículo, se abordará el tema de desigualdad de género como una dimensión de la desigualdad socioeconómica presente en Costa Rica. Por medio de la evaluación de una serie de variables socioeconómicas de relevancia, se demuestra que a pesar de que el país ha avanzado en materia de reconocimiento de los derechos de las mujeres, todavía queda mucho por hacer para que esto se vea acompañado por una condición de mayor igualdad en el acceso y propiedad a activos productivos, así como en mejores y mayores oportunidades de empleo productivo.

PALABRAS CLAVE: COSTA RICA * MUJERES * IGUALDAD DE GÉNERO * POTENCIACIÓN DE LAS MUJERES * INGRESO * POBREZA

\section{ABSTRACT}

For the purposes of this article, we address gender inequality as a dimension of socioeconomic inequality expressed in Costa Rica. Through the evaluation of a series of socioeconomic variables, we show that even when the country has moved forward in terms of recognition of women rights, there is still much to do to achieve greater levels of equality in the access to productive resources, socio-economic assets and employment.

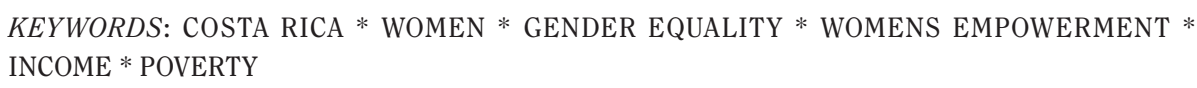

1 Este artículo es producto del proyecto de investigación de la Escuela de Economía de la Universidad Nacional de Costa Rica, titulado "Análisis de las dimensiones de la desigualdad socioeconómica en Costa Rica".

* Instituto de Investigaciones en Ciencias Económicas de la Universidad de Costa Rica (IICE-UCR). Escuela de Economía de la Universidad Nacional de Costa Rica (UNA).

arias63@gmail.com 


\section{INTRODUCCIÓN}

Es importante entender que las desigualdades socioeconómicas no son solo un problema de mala distribución de los ingresos. La desigualdad asume distintas dimensiones, siendo la dimensión de género una de las más importantes de ser analizadas a la luz de las principales variables e indicadores en materia de equidad de género. De tal forma, el país tiene todavía importantes desafíos respecto a un conjunto de brechas de género que persisten y que están asociadas con problemas estructurales, tales como: la feminización de la pobreza, la falta de reconocimiento del trabajo femenino $y$ desfavorables condiciones de inserción laboral, incluyendo brechas de ingreso y segmentación del mercado laboral. Las estadísticas señalan la situación de desventaja en la que se encuentran las mujeres en el mercado de trabajo en Costa Rica; esto porque a pesar de mayores niveles de educación de las mujeres, las tasas de empleo femenino siguen siendo bajas y los problemas relacionados con la segmentación y segregación del mercado laboral continúan siendo evidentes (Programa Estado de la Nación, 2005).

En la actualidad, es innegable la importancia de la participación de la mujer en distintos ámbitos de la sociedad costarricense. Avances en cuanto a la participación y representación política, así como, una mayor inserción en el mercado laboral, son resultados de una serie de reivindicaciones de las mujeres, las cuales se han visto materializadas en cambios institucionales y en la definición de políticas de reconocimiento de los derechos que las asiste como ciudadanas.

No obstante, los avances significativos en cuanto a políticas de reconocimiento $y$ distribución que las mujeres han logrado en las últimas dos décadas - tanto en función de igualdad de género como en la creación de oportunidades y capacidades - todavía se encuentran brechas importantes que hacen que las desigualdades de género persistan en varios ámbitos. Dentro de la inserción y participación en el mercado de trabajo, así como, en el acceso a la educación y la salud, existen con una serie de desigualdades que requieren de políticas públicas con un diseño e implementación efectivas en su reducción.
Uno de los aspectos más serios en materia de desigualdades que afectan a las mujeres es la situación que tiene que ver con el significativo porcentaje de hogares jefeados por mujeres que se encuentran en una situación de pobreza o con altos niveles de vulnerabilidad a caer en dicha condición. La condición de pobreza de un importante porcentaje de los hogares donde la mujer representa la principal fuente de ingresos, impone obstáculos estructurales para poder superar el ciclo vicioso de la pobreza que afecta a dichos hogares $y$ a sus miembros, muchos de los cuales son menores de edad.

Por las razones anteriores, el análisis de la dimensión de género es una condición necesaria en el estudio de las desigualdades y la pobreza que afectan a las mujeres en Costa Rica.

\section{CONSIDERACIONES TEÓRICAS SOBRE LA EQUIDAD DE GÉNERO}

La equidad es concebida como el acceso de las personas a la igualdad de oportunidades y al desarrollo de las capacidades básicas; esto significa que se deben eliminar las barreras que obstaculizan las oportunidades económicas y políticas, así como, al acceso a la educación y a los servicios básicos, de tal manera que las personas (hombres y mujeres de todas las edades, condiciones $y$ posiciones) puedan desarrollar dichas capacidades para mejorar sus niveles de bienestar. Esto significa la participación de la totalidad de la ciudadanía en los procesos de desarrollo económico y social en un contexto de igualdad de oportunidades $y$ de un Estado que se preocupa por el desarrollo de las capacidades de sus habitantes, reconociendo el derecho a la diferencia y el respeto a la diversidad en sus distintas manifestaciones (Alfaro, 1999).

El enfoque de género implica también la revisión de las capacidades de las instituciones existentes y sus mecanismos de acción afirmativa para avanzar hacia la igualdad entre mujeres $y$ hombres. Por un lado, es fundamental reconocer que las mujeres y los hombres tienen condiciones de vida, necesidades e intereses diferentes, según el contexto cultural, económico, político, ideológico y ambiental en que se desarrollen; por otro, que las políticas no son "neutras" en cuestiones de género. En 
este sentido, se hace necesario revisar el instrumental técnico, conceptual y político desde el cual se conciben y diseñan las estrategias de intervención pública por parte del Estado y que afectan el desarrollo de capacidades y oportunidades para las mujeres (Programa Estado de la Nación, 2007).

Dado que la condición de género históricamente se ha expresado en distintas formas de desigualdad, el enfoque de género es de utilidad para entender el estatus social diferenciado de mujeres y hombres, así como, el impacto que esto tiene en la organización de las instituciones sociales. En este sentido, para lograr la igualdad, se debe promover también la equiparación de condiciones desiguales y favorecer la capacidad de agencia e incidencia política de las personas, particularmente de las mujeres. Para ello es fundamental consolidar e impulsar una pluralidad de acciones afirmativas $y$ de principios normativos. Este enfoque obliga a mirar cualquier situación social o programa de intervención desde una perspectiva que permita entender las necesidades específicas de mujeres y hombres; es decir, un análisis desde la igualdad de género, el cual comprende las necesidades prácticas y estratégicas, así como, las restricciones, las oportunidades y las opciones de mujeres $y$ hombres en un determinado contexto social.

\section{CREACIÓN DE CAPACIDADES PARA EL DESARROLLO HUMANO: UN ENFOQUE PARA LA EQUIDAD DE GÉNERO}

De acuerdo con Sen (1995), el principal fin del desarrollo es ampliar las posibilidades de las personas para que estas puedan elegir la vida que desean, por lo que la igualdad de oportunidades de ser y actuar juega un papel fundamental. El proceso de ampliación de las opciones de las personas no puede tener lugar cuando se restringen sus oportunidades, en razón de desigualdades por cuestiones de edad, etnia, ubicación geográfica o género, tanto en las esferas social y económica, como en materia de derechos civiles y políticos. Para este autor, acceder $y$ controlar los recursos materiales no es un objetivo en sí mismo, pero si un medio para el desarrollo de capacidades en un marco institucional de libertad $y$ derechos.

Para Nussbaum (2002), la concepción de capacidades de Sen es relevante para la construcción de la equidad de género. De acuerdo con esta autora, el enfoque de capacidades supone darle el lugar central a la agencia de la persona, con el fin de realizarse en plenitud. Esto implica pensar en la equidad de género como la capacidad de las personas de realizarse en lo que sean capaces de "hacer y ser" (Hicks, 2002).

Es así como el enfoque de creación de capacidades se convierte en un componente central del desarrollo humano, coherente con las aspiraciones de las mujeres en materia de equidad e igualdad de oportunidades. De tal manera, el desarrollo humano se concibe como:

... un proceso continuo e integral que reúne componentes $y$ dimensiones del desarrollo de las sociedades $y$ de las personas, en los que resulta central la generación de capacidades $y$ oportunidades de, por y para éstas personas, con las que la equidad se acreciente para las actuales y futuras generaciones (Programa Estado de la Nación, 1994:78).

Por lo tanto, el proceso de desarrollo busca no solo brindar la satisfacción de las necesidades básicas, sino también la participación efectiva de hombres $y$ mujeres en igualdad de condiciones, en la toma de decisiones y en el diseño de la política pública para el desarrollo humano sostenible.

De tal forma, el desarrollo humano sostenible con igualdad de género promueve la igualdad de derechos entre mujeres $y$ hombres, reconociendo y respetando la diversidad de su condición humana, la consideración de las mujeres como agentes $y$ beneficiarias del desarrollo, la ampliación de las oportunidades para mujeres y hombres; generando igualdad de condiciones para que ambos grupos accedan a las oportunidades $y$ a mayores niveles de bienestar objetivo y subjetivo (Programa de las Naciones Unidas para el Desarrollo-pnud, 2005).

Otra perspectiva que forma parte y complementa el enfoque de creación de capacidades de Sen, es el enfoque de derechos, el cual 
implica un cambio significativo en la concepción tradicional de la atención a las personas. Este reconoce que todas las personas, independientemente de su género, edad, cultura, nacionalidad o cualquier otra condición, son titulares de toda la gama de derechos inherentes a su condición humana. También plantea que el Estado $y$ la sociedad en general, deben garantizar los espacios, las oportunidades y las condiciones necesarias para que todas las personas desarrollen sus potencialidades $y$ hagan uso pleno de sus derechos ciudadanos (Instituto Interamericano de Derechos Humanos-IIDH, 2005).

En este sentido, las desigualdades sociales y de identidad, en particular las de género, se convierten en obstáculos, tanto para la obtención de ingresos como para el desarrollo de capacidades de segmentos de la población que sufren de exclusión y discriminación por sus diferencias. Por lo tanto, la noción de desarrollo humano, no puede separarse del logro de la autonomía y del "empoderamiento"2 económico, social y político de las mujeres. La autonomía comprende la conquista de independencia económica a través del acceso al empleo productivo $y$ a la propiedad de activos. Mientras el enfoque de capacidades destaca como componente primordial el acceso a bienes y servicios como la salud y la educación (capacidades básicas), acceso a activos, al empleo productivo y a la libertad; el empoderamiento destaca los aspectos relacionados con la participación efectiva en el proceso de toma de decisiones. En el marco de las interpretaciones feministas del poder, más allá de sus definiciones formales e institucionales, el empoderamiento es algo más que abrir el acceso al proceso de toma de decisiones; sino que este también incluye los procesos que llevan a las personas a percibirse a sí

$2 \quad$ El concepto de empoderamiento tiene diversos orígenes y desarrollos, siendo utilizado por numerosos movimientos sociales desde los años $60 \mathrm{y}$ asumido por el movimiento de mujeres desde los años 70. Este concepto se utiliza en el contexto del desarrollo económico y social para hacer referencia a la necesidad de que las personas como sujetos de la acción de desarrollo, se fortalezcan en su capacidad de tomar sus propias decisiones en un marco de derechos y libertad de acción. mismas con la capacidad y el derecho a ocupar ese espacio decisorio.

$\mathrm{El}$ fin del desarrollo es generar bienestar, por tanto, es importante que en su análisis $y$ promoción se atiendan asuntos críticos como: los roles de hombres y mujeres, sus responsabilidades, desafíos y restricciones en los distintos ámbitos de la vida en sociedad. La igualdad de género tiene que ser un objetivo explícito de la agenda de desarrollo, para lo cual se deben impulsar arreglos institucionales y diseñar e implementar tanto políticas de reconocimiento como de redistribución, dirigidas a sustentar la igualdad de oportunidades sin exclusión, tanto ante la ley como ante las instituciones.

Para Kabeer (2005), una manera de pensar el poder es en términos de la capacidad de elegir, refiriéndose al proceso a través del cual aquellos a los que se les ha negado dicha capacidad, la adquieren. Se trata así de la capacidad de las mujeres de incrementar su propia auto confianza en la vida e influir en la dirección del cambio, mediante la habilidad de obtener derechos y control sobre los recursos (físicos, humanos, intelectuales, financieros y el de su propio ser) y sobre la ideología (creencias, valores $y$ actitudes).

En este sentido, el principio de equidad remite a la diversidad $y$ al reconocimiento de las desigualdades, de la inequidad en las posibilidades de los seres humanos para acceder a las oportunidades para mejorar sus vidas. Dicho principio parte de identificar las diferentes formas de participar en el ámbito social evidenciando desigualdades. Por ejemplo, las situaciones discriminatorias que enfrenta la mayoría de las mujeres, han puesto de manifiesto las limitaciones que afectan el goce y ejercicio de sus plenos derechos y que les impide mejorar sus condiciones de vida (IIDH, 2004).

La igualdad de derechos de las mujeres es un principio fundamental contemplado en la Declaración Universal de Derechos Humanos, así como, en los instrumentos principales de derechos humanos, tales como, el Pacto Internacional de Derechos Civiles y Políticos, y el Pacto Internacional de Derechos Económicos, Sociales y Culturales. En estas declaraciones se establece que los derechos son aplicables 
a todas las personas, sin distinción alguna de etnia, sexo, idioma, religión, opinión política o de otra índole, origen nacional o social, posición económica, nacimiento o cualquier otra condición social. Además, los Estados parte se comprometen específicamente a garantizar a hombres y mujeres, la igualdad en el goce de todos los derechos económicos, sociales, culturales, civiles y políticos.

Estos compromisos ganan importancia en un contexto de transformaciones que se caracterizan por los cambios en el Estado nacional y las formas de su soberanía, así como, en su papel en la protección de los derechos ciudadanos. De tal forma, son cada vez más los casos en los que la justicia internacional adquiere relevancia a través de sus instrumentos internacionales para la protección, defensa y ejercicio de dichos derechos. Uno de los casos significativos tiene que ver con la afirmación de los derechos y la igualdad de las mujeres (Comisión Económica para América Latina y el Caribe-cepal, Oficina del Alto Comisionado para los Derechos Humanos-OACDH y Committee on the Elimination of Discrimination against Women-cEDAw, 2005).

\section{POLÍTICA DEL RECONOCIMIENTO Y POLÍTICA DE LA REDISTRIBUCIÓN}

El debate sobre la equidad de género ha capturado la atención de la investigación teórica en las últimas dos décadas. Es particularmente interesante la discusión académica entre dos enfoques teóricos, ricos en sus fundamentos $y$ planteamientos centrales en torno a una explicación epistemológica de las condiciones sociales, políticas y culturales que construyen $y$ explican una participación desigual e injusta de las mujeres en la sociedad. Es así como la política del reconocimiento y la política de la redistribución han ocupado un espacio vital en la discusión académica, con aportes y contribuciones que han enriquecido nuestra aproximación al problema de la justicia social y cultural, que afecta a distintos grupos de la sociedad, ya sea por su condición de género, raza o etnicidad.

Las políticas del reconocimiento existen y surgen desde la lógica de que el reconocimiento inexacto y la representación distorsionada de una identidad social o colectiva producen una serie de efectos adversos para quienes forman parte de esa identidad. Estos efectos se pueden manifestar tanto en las cuotas de participación y acceso político y económico, así como, en una serie de narrativas $y$ discursos que pueden servir como formas de limitar el accionar individual y colectivo de una identidad o un grupo social en particular.

Asimismo, el reconocimiento (fiel o distorsionado) además de generar diversas concepciones de la sociedad hacia un determinado grupo o identidad, también genera concepciones propias e internalizadas, en quienes forman parte de este. Estas concepciones propias, que inciden en la definición del "yo", también pueden servir como medios de limitación del accionar individual y colectivo. Por lo tanto, las demandas por el reconocimiento no solo sirven para transformaciones estructurales $e$ institucionales, sino también como medios de emancipación individual y colectiva.

Es necesario enfocar la manera en que se reconoce o no el género. En la construcción identitaria nunca hay una sola fuente o referencia de la identidad; es decir, no es la dicotomía reduccionista mujer vs. hombre o viceversa. La identidad se constituye por medio de diversas fuentes, sean estas sexuales, étnicas, culturales, geográficas y políticas. En este sentido, Young (1994) expresa que sería absurdo pensar el género como algo autónomo de fuentes, por ejemplo, la etnicidad o la clase económica.

Otro aspecto importante a tomar en cuenta cuando se analizan políticas de reconocimiento en el tema de género, es su carácter evolutivo y dinámico. Así como la identidad es dinámica y cambia constantemente, el género también lo es. Esto dado que los roles de género se transforman con sus contextos y sus narrativas, por lo tanto, se evidencia la complejidad del género en la lógica de las políticas de reconocimiento. Esta característica de alto dinamismo rechaza cualquier intento de concebir el género de manera esencialista o estático, sino más bien como una construcción social e histórica.

Concebir el género como una construcción social e histórica, tiene implicaciones relevantes para la política en cuestión. Por un lado, 
es necesario entender la diversidad de fuentes que constituyen la identidad, pues el género es una de esas fuentes que al mismo tiempo se retroalimenta $y$ se construye a partir de las demás identidades y su contexto social. Esto plantea que la construcción identitaria es un proceso dialéctico, que se expresa en constantes transformaciones $y$ tensiones institucionales $y$ discursivas, que a su vez se reflejan en nuevas formas de representación, reconocimiento y acción de los actores sociales.

La política del reconocimiento establece su enfoque desde la esfera social y cultural. De tal manera, las desigualdades entre grupos sociales son consecuencia de las diferencias en cuanto a representación y participación en los distintos ámbitos del desarrollo, lo cual limita la consecución de mayores niveles de equidad y la construcción de una sociedad más justa. En este sentido, Young (1990) presenta una posición crítica respecto al problema de la desigualdad, exponiendo una perspectiva para entender la igualdad y la justicia a partir del análisis de la estructura social y especialmente, desde las dinámicas de la opresión y la dominación. Estas dinámicas se ejercen sobre las capacidades de autodeterminación y autodesarrollo que tienen los distintos grupos sociales y estas se manifiestan en los siguientes cinco elementos: explotación, marginación social o laboral, carencia de poder, imperialismo cultural y violencia de diverso tipo.

Para esta autora, la desigualdad no se puede reducir a aspectos meramente redistributivos, pues se pueden obviar las múltiples dimensiones que asume la injusticia social $y$ la exclusión. Por esta razón, es necesario abordar la desigualdad desde una perspectiva socioeconómica y cultural, que permita entenderla, no solo como un problema de acceso a los medios de producción y subsistencia, sino también como un problema de estatus, en cuanto a la falta de reconocimiento $y$ representación en las distintas instituciones, el proceso de toma de decisiones, así como, el diseño y definición de políticas públicas. Young (1990) aporta un aspecto fundamental en la metodología del estudio de la desigualdad, el cual va más allá de la definición de políticas para reducir las desigualdades, para abordar también la necesidad de entender y transformar estructuras que las crean, sostienen $y$ reproducen.

Por su parte, Taylor (1994) en su ensayo acerca del multiculturalismo y las políticas de reconocimiento, argumenta que estas últimas trabajan en dos esferas diferentes: la íntima y la pública. En la esfera íntima, el reconocimiento es un medio por el cual el individuo se identifica $y$ hasta cierto grado, se define. Mientras tanto en la esfera pública, el reconocimiento es un medio por el cual un determinado grupo social se puede realizar en una sociedad diversa. La negación de sus identidades, el falso reconocimiento y la creación de estereotipos pueden obstaculizar, excluir y hasta oprimir el desarrollo y la conservación de la identidad de diversos grupos sociales.

Al ser esencialmente un tema cultural $y$ social, el reconocimiento se entiende como la columna vertebral para el desarrollo de una sociedad democrática y pluralista. Esto bajo la lógica de que a mayor reconocimiento de las particularidades e identidades de los distintos grupos de la sociedad, mayor la posibilidad de promover relaciones sociales más inclusivas $y$ democráticas. Por lo tanto, la tesis de la política del reconocimiento no es solamente la igualación de derechos y deberes, sino también la conservación de la dignidad, el respeto a la diferencia $y$ la identidad de cada grupo social. Es en este sentido que Taylor (1994) expone el reconocimiento igualitario como medio de diálogo democrático.

A diferencia del enfoque del reconocimiento, el enfoque de la redistribución se enmarca en un ámbito que explica la desigualdad desde una perspectiva económica y estructural de la concentración de la riqueza y de la reproducción del rol histórico y tradicional de la mujer en el ámbito de lo doméstico. Es por esto que los teóricos de la redistribución argumentan que, en términos de reconocimiento $y$ la diferencia, los distintos grupos sociales pueden ser definidos económicamente y así tener mayor visibilización y relevancia en el proceso de reforma y reestructuración económica. 
Una de las diferencias más importantes entre las políticas de reconocimiento y las políticas de redistribución, es la concepción respecto a la desigualdad. A diferencia de las políticas de reconocimiento, las políticas de redistribución entienden las desigualdades sociales desde la lógica de acumulación y apropiación del capital y la estructura de clases. A partir del enfoque de la redistribución, se aborda el problema de la exclusión social y la desigualdad como resultado de relaciones sociales $y$ materiales de producción, que no solo reproducen estructuras desiguales entre clases sociales, sino que transversa ámbitos de desigualdad étnica, racial $y$ de género.

Ante los problemas de desigualdad, las políticas de redistribución se enfocan en las estructuras económicas que causan y sostienen dichas desigualdades. De tal manera, al ser este enfoque predominantemente económico, las desigualdades son identificadas según clases socioeconómicas. Por esta razón, las desigualdades son relacionadas directamente con factores económicos, como el acceso y participación en los mercados, el empleo productivo y la relación social con los medios de producción, entre otros.

Para reducir las desigualdades socioeconómicas, la política de la redistribución promueve un cambio de las estructuras económicas buscando crear mecanismos, reformas económicas e institucionales que promuevan una distribución más igualitaria de los recursos, una mayor inserción en la vida productiva y al empleo productivo, así como, el acceso a bienes y servicios para el desarrollo de las capacidades productivas, principalmente de aquellos grupos en desventaja.

En este sentido, Fraser (1996) plantea la necesidad de integrar los desafíos de reconocimiento con los desafíos de la redistribución en la sociedad contemporánea. La conclusión es que tanto el reconocimiento como la redistribución son componentes indisolubles para una solución a los problemas de discriminación y falta de representación que afectan a los distintos grupos sociales, que por su condición de género, de origen étnico y racial, padecen de marginación social y de una vida sin plenos derechos.

Desde el enfoque de la redistribución, en el tema de género, se pueden identificar varios problemas que involucran la explotación laboral, la marginación económica, la invisibilización de actividades productivas en el ámbito de lo doméstico y las diferencias en el acceso al empleo y activos productivos. Estas desigualdades al ser fundamentalmente distributivas, requieren de reformas estructurales no solo en términos del acceso y control de los medios de producción, sino también en cuanto al papel del Estado, mediante políticas redistributivas que promuevan y no discriminen el desarrollo de capacidades objetivas y subjetivas de las mujeres.

Por su parte, para la política del reconocimiento, las desigualdades se explican por estructuras institucionales, así como, contextos históricos y culturales que han construido $y$ perpetuado condiciones de injusticia. Bajo dichas circunstancias históricas, las mujeres han sido víctimas de un falso reconocimiento en sociedades predominantemente patriarcales, donde el rol de la mujer ha sido relegado a niveles de participación marginal en la vida social, económica, política y cultural. Esta situación ha reproducido una pérdida histórica de representación, participación y ejercicio de los derechos, los cuales son principios indispensables para el desarrollo en libertad.

Es claro que ninguno de los dos enfoques de políticas podría subsanar el tema de género en su complejidad. Después de un debate controversial de largo tiempo, Fraser (1996) ha llegado a la conclusión de que el género está sujeto tanto a la condición de clase económica como de estatus social. Fraser (1994) propone entender la equidad de género desde su complejidad y no desde una concepción reduccionista del concepto. Para esto, establece que es necesario romper la concepción de que la equidad de género está sujeta únicamente a variables económicas o culturales. Por el contrario, es la interrelación de dichas variables y sus implicaciones la que llama la atención respecto a la necesidad de avanzar hacia una interpretación de la complejidad multidimensional de los problemas de género, los cuales pasan tanto por 
aspectos de redistribución como de reconocimiento y representación.

El debate y las contribuciones teóricas de ambos enfoques, han demostrado la relevancia y complementariedad de la política de la redistribución y de la política del reconocimiento para entender el género desde una perspectiva epistemológica y como una construcción social y cultural. La confluencia de los enfoques del reconocimiento y la redistribución también proveen los criterios necesarios para el diseño e implementación de políticas públicas y reformas institucionales para la promoción de mayores niveles de equidad de género.

En el análisis de las dimensiones de las desigualdades socioeconómicas en Costa Rica, las que corresponden a género han merecido una atención especial, tanto desde el punto de vista teórico como desde el punto de vista empírico. Se trata con uno de los temas más sensibles en materia de reconocimiento y redistribución, ya que el tema de equidad de género tiene explicaciones desde lo cultural-simbólico, lo social y lo económico. Por lo tanto, un análisis integrado de ambos enfoques como el que propone Fraser (1996) es de gran utilidad.

En particular, en este artículo se ha realizado un análisis y evaluación de la desigualdad de género en el país, a partir de lo que se considera que se ha avanzado en materia de política del reconocimiento y política de redistribución. Se propone establecer los alcances y vacíos en cuanto a ambas políticas; así como a identificar las brechas todavía existentes entre lo que se tiene en materia de reconocimiento y lo que realmente se ha traducido en materia de redistribución en Costa Rica.

\section{POLÍTICA DE RECONOCIMIENTO PARA LA IGUALDAD DE GÉNERO EN COSTA RICA}

El principio de igualdad no se define a partir del criterio de semejanza sino de justicia: se otorga el mismo valor a personas diversas, integrantes de una sociedad. La igualdad es importante justamente entre diferentes, ya que se trata de una convención social o un pacto, según el cual se reconoce como iguales a quienes pertenecen a distintos sexos, etnias $y$ clases sociales. En el marco de los derechos de las mujeres, hablar de igualdad no significa identidad con los hombres, significa tener las mismas oportunidades, ser reconocidas $y$ tratadas como iguales, reconociendo $y$ respetando la diversidad de sus identidades y condiciones humanas (Instituto Nacional de las MujeresINAMU, 2007a).

Otro principio complementario de la igualdad es la equidad, que remite a la diversidad $y$ al reconocimiento de las desigualdades $y$ de la inequidad en las posibilidades de los seres humanos a acceder a las oportunidades para mejorar sus vidas. Las situaciones discriminatorias que enfrentan la mayoría de las mujeres, han puesto de manifiesto las limitaciones que afectan el goce $y$ ejercicio de sus plenos derechos y que les impide mejorar sus condiciones de vida (IIDH, 2005).

A partir del año 2002 y hasta la actualidad, luego de una época de acelerados avances, los esfuerzos a favor del cierre de brechas de género se volvió más lento y costoso; con logros apenas marginales en comparación con los vertiginosos cambios de la década previa. Esto ocurre en un contexto nacional en el que existen problemas estructurales importantes, tales como: la agudización de la pobreza de las mujeres, la desigual remuneración en igualdad de condiciones del trabajo femenino, desfavorables condiciones de inserción laboral y segmentación del mercado de trabajo. Aunado a lo anterior, habría que considerar la prevalencia de condiciones discriminatorias en asuntos relativos a la educación como la segregación de matrícula en formación profesional, la violencia en contra de las mujeres, los rezagos institucionales y la escasez de recursos asignados al diseño y ejecución de políticas públicas específicas. Esto último ocurre debido a crecientes restricciones fiscales del Estado costarricense, pero también a una creciente dispersión y vacíos de dirección entre los diversos Poderes de la República y sus instituciones.

Dentro del marco institucional internacional, el país como miembro de la Organización de Naciones Unidas (onu) y de la Organización de Estados Americanos (oEA), ha ratificado declaraciones y convenios aprobados por ambos organismos. Entre ellos están 
la Convención sobre la Concesión de los Derechos Políticos de la Mujer, declarada por la OEA en 1948; el Tratado sobre Derechos Civiles y Políticos y la Convención sobre los Derechos Políticos de la Mujer en 1967. Esta última convención ratifica el derecho de las mujeres a votar en todas las elecciones en igualdad de condiciones que los hombres y sin discriminación alguna, así como, su elegibilidad para todos los órganos públicos y su derecho a ocupar cargos y ejercer todas las funciones públicas. La Convención sobre la Eliminación de Todas las Formas de Discriminación contra la Mujer, aprobada por la onu en 1979, entró en vigor en 1981 y fue ratificada por Costa Rica en 1985. El Protocolo Facultativo de la Convención fue ratificado por Costa Rica en septiembre del 2001 (IIDH, 2005). Asimismo, en octubre de 1995, el Estado costarricense ratificó la Convención Interamericana para Prevenir, Sancionar y Erradicar la Violencia Contra la Mujer, conocida como la Convención de Belem do Pará.

Dentro del plano nacional se han producido avances institucionales importantes, como la constitución del Instituto Nacional de las Mujeres, la Defensoría de la Mujer en la Defensoría de los Habitantes, fiscalías especiales en el poder judicial $y$ las comisiones $y$ oficinas municipales de la mujer. De igual forma, nueva legislación ha sido adoptada, como la Ley contra la Violencia Doméstica, la Ley contra el Hostigamiento Sexual y la Ley de Penalización de la Violencia Doméstica del 2007.

En el plano político, destaca la reforma al Código Electoral de 1996 (Ley 7653), que estableció una cuota mínima del $40 \%$ de participación femenina en las instancias partidarias y en las papeletas para los puestos de elección popular. Se suma a este hito histórico, una serie de resoluciones posteriores del Tribunal Supremo de Elecciones (TSE) en las que se aclaran las obligaciones y responsabilidades de los partidos políticos en el acatamiento de esa cuota mínima (Inamu, 2007c).

Un segundo hito histórico en el país en el avance de la institucionalidad a favor de la igualdad de género, estuvo caracterizado por el diseño y puesta en marcha del Plan Nacional de Igualdad de Oportunidades entre Mujeres y Hombres (ріонм). El mismo fue elaborado durante la Administración Figueres Olsen (19941998) y estuvo a cargo del Centro Nacional para el Desarrollo de la Mujer y la Familia. El ргонм fue un plan ambicioso, que recogió importantes necesidades e intereses de las mujeres expresados en ocho ejes de trabajo, 47 objetivos y 192 acciones estratégicas, involucrando a 32 instituciones responsables de su ejecución.

A la aprobación del ріонм se sumó posteriormente, el diseño de varios agregados propuestos como los planes sectoriales en materia agropecuaria y ambiental (1997), así como, en el sector salud, propuesto por la Caja Costarricense del Seguro Social (1998). Estos planes buscaron ampliar el alcance de las medidas propuestas inicialmente en el ріонм. Además del ріонм, a partir de 1994, se incorporaron ejes para atender problemas y necesidades específicas de las mujeres dentro de los Planes Nacionales de Desarrollo.

Un tercer hito que tuvo lugar en los 90 fue la aprobación de la Ley de creación del Instituto Nacional de las Mujeres (inamu) en 1998 (nro. 7801), la cual elevó al entonces Centro Nacional para el Desarrollo de la Mujer y la Familia (смғ) a rango de institución autónoma. La creación del Inamu se convierte en un arreglo institucional de relevancia en términos de la representación de los intereses y aspiraciones de las mujeres costarricenses. Además, la ley del Inamu estableció como mandato del Instituto, la formulación de la política nacional para la igualdad de género, tal y como se consigna en su art. $3^{\circ}$ que señala entre sus fines el de: "Formular e impulsar la política nacional para la igualdad $y$ equidad de género, en coordinación con las instituciones públicas, las instancias estatales que desarrollan programas para las mujeres y las organizaciones sociales" (Ley 7801, 1998).

Paralelamente, durante la última década, la creación de institucionalidad a favor de la igualdad y la equidad de género, trascendió al Gobierno Central y se extendió rápidamente al conjunto del Estado. Es así como el Poder Ejecutivo, el Poder Judicial y los Gobiernos Locales crearon diversos mecanismos, 
introdujeron cambios normativos $y$ definieron políticas públicas a favor de las mujeres y la equidad de género. Por su parte, el Tribunal Supremo de Elecciones, dentro de su ámbito jurisprudencial, se convirtió en el garante de la aplicación de los derechos políticos de las mujeres. Por otra parte, el Poder Legislativo, modifica el artículo 84 del Reglamento de la Asamblea Legislativa que crea la Comisión Permanente Especial de la Mujer, la cual conoce y dictamina proyectos de ley que afectan las diversas situaciones de las mujeres (inamu, 2007c).

Otro aspecto a resaltar es el que tiene que ver con la creación de unidades académicas especializadas en las universidades públicas del país, en torno a temas de género. Esto ha contribuido con el análisis teórico y metodológico en asuntos de género y también en la generación de información relevante para informar el proceso de diseño e implementación de política pública en una serie de ámbitos relacionados con la igualdad de género. Por su parte, la formación de profesionales y la realización de estudios que constituyeron importantes insumos para el desarrollo institucional, han posicionado algunos temas de género en la agenda de desarrollo nacional. Estas instancias son: el Centro de Investigación en Estudios de la Mujer (СIEм-ucR), el Instituto de Estudios de la Mujer (IEM-UNA), el Programa Institucional para la Equidad de Género (PIEG-uned), el Programa de Equidad de Género (IтсR) y el Programa de Maestría en Estudios de la Mujer (UNA-UCR).

Actualmente, con la entrada en vigencia de la nueva política institucional para la igualdad y equidad de género, aprobada por la Comisión de Género del TSE, en Sesión Extraordinaria nro. 10-2008, art. 2, del 25 de agosto de 2008, se da un respaldo a un proceso de construcción fundamentado en la orientación gubernamental y la participación activa de mujeres y hombres. Asimismo, con base en los enfoques mencionados, la PIEg es producto de una intencionalidad acordada entre actores individuales $y$ colectivos.

Los avances significativos en cuanto a políticas de reconocimiento que las mujeres han logrado en las últimas dos décadas, tanto en función de equidad de género como en la creación de oportunidades y capacidades, se plasman en los ejes y acciones estratégicos de esta política de igualdad de género. Desde la inserción y participación en el mercado de trabajo, hasta el acceso a educación y salud. Estas políticas deben poseer carácter imperativo en la búsqueda de la reducción de la desigualdad a la que se hace referencia en este artículo. Estas acciones buscan generar cambios que contribuyan con el cierre de brechas de género relacionadas con el empleo y los ingresos, las responsabilidades familiares, la educación y la salud, la protección efectiva de los derechos y la participación política de las mujeres (ver figura 1). 


\section{FIGURA 1}

EJES ESTRATÉGICOS DE LA POLÍTICA DE IGUALDAD DE GÉNERO COSTA RICA

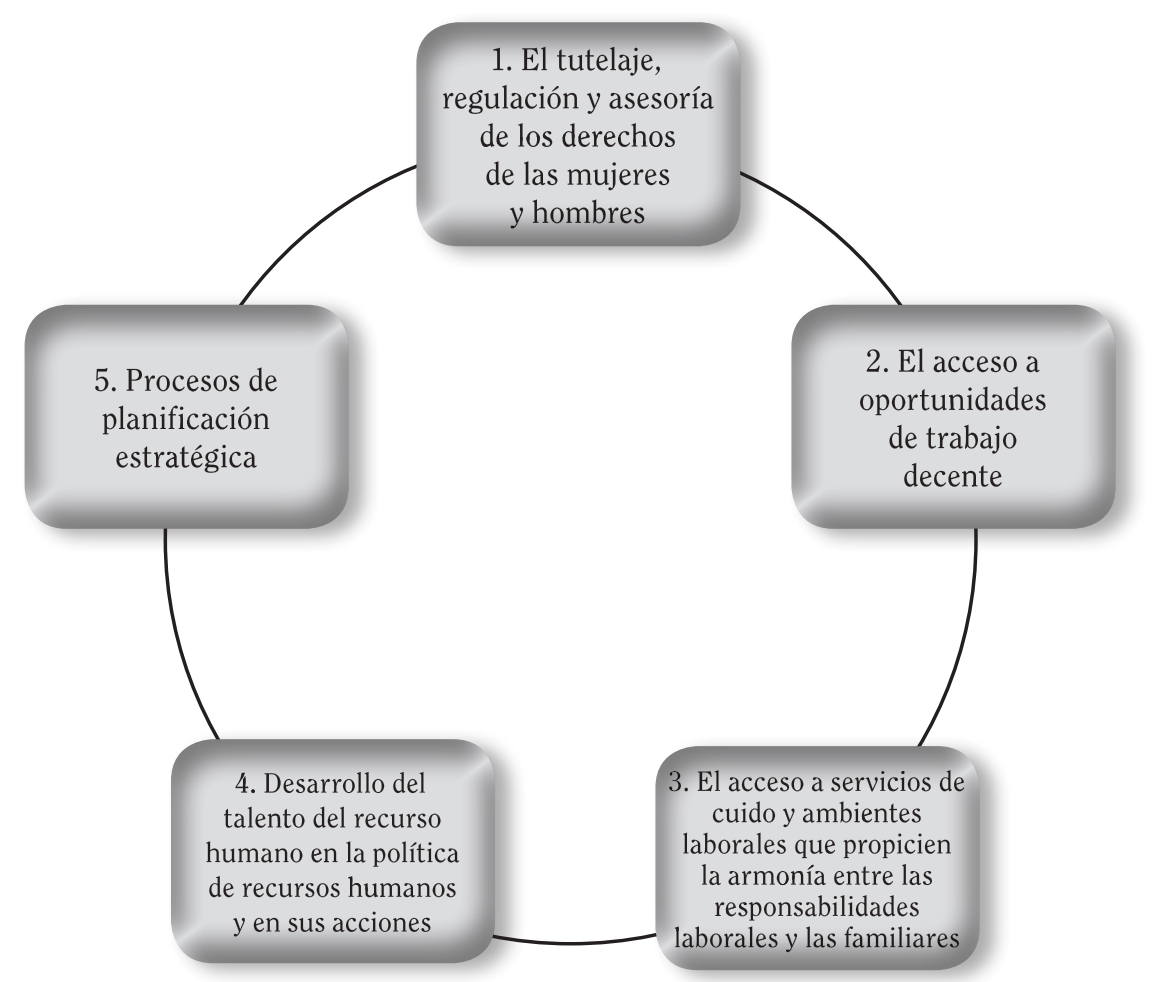

Fuente: Elaboración propia a partir de datos del PIEG, 2007-2010.

Este comportamiento se ve reflejado en el aumento del gasto para la institución rectora del tema de género en el país, como lo es el inamu, que en los últimos diez años ha venido creciendo de manera significativa, no solo en términos presupuestarios, sino también en su incidencia en la definición de políticas y normativa referentes a los derechos de las mujeres (ver gráfico 1). 
GRÁFICO 1

EVOLUCIÓN DEL PRESUPUESTO DEL INSTITUTO NACIONAL DE LAS MUJERES

EN COSTA RICA 2001-2010

(EN MILES DE COLONES)

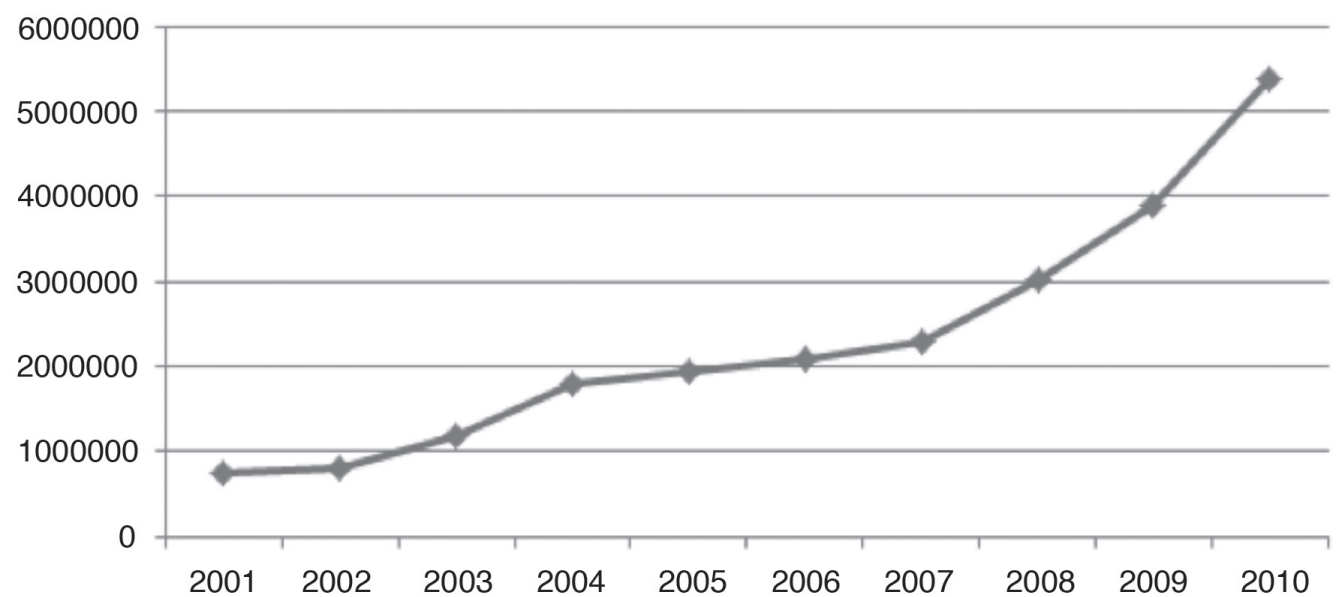

Fuente: Elaboración propia a partir de datos del Ministerio de Hacienda, 2001-2010.

El inamu se financia con el $2 \%$ del presupuesto de Fondo de Desarrollo Social y Asignaciones Familiares (fodesaf). Algunas de las críticas a la administración presupuestaria del INAMU tienen que ver con problemas para garantizar una ejecución eficiente y eficaz de sus recursos en algunos de sus principales programas. Por ejemplo, para el 2010, solo se ejecutó el $58 \%$ de los recursos destinados al programa de atención de las mujeres en condición de pobreza. Parte de esta inoperancia se presenta por la imposibilidad legal del inamu de incidir en las decisiones de las entidades públicas externas relacionadas con su funcionamiento. Este es el caso del Instituto Mixto de Ayuda Social (imas), el cual no pudo cumplir oportunamente con la responsabilidad de asignar incentivos económicos a este grupo de la población. La sub ejecución presupuestaria no solo ha afectado programas de interés social y de inversión para el desarrollo de las capacidades de las mujeres, sino que ha afectado la misma imagen de la institución (Inamu, 2011).

De lo expuesto anteriormente, es evidente que durante los últimos 15 años, el marco jurídico e institucional sobre la igualdad y equidad de género ha experimentado transformaciones a nivel internacional y nacional. En este último ámbito, el Estado costarricense inició el desarrollo de una serie de acciones institucionales para la promoción de la igualdad y la equidad de género. En este proceso fue significativa la influencia de las organizaciones de mujeres, que incidieron de manera determinante mediante la diversificación de sus formas organizativas y la diversidad de las demandas planteadas frente al Estado, en la constitución de nuevos espacios institucionales y en la promoción de un marco normativo favorable a los derechos e intereses de las mujeres (Goldemberg, 2006).

POLÍTICA DE LA REDISTRIBUCIÓN: ANÁLISIS DE LAS BRECHAS EN DISTRIBUCIÓN Y LAS DESIGUALDADES DE GÉNERO EN COSTA RICA PARA EL PERÍODO 2000-2010

Costa Rica, cuya posición en materia de equidad de género es destacada en América Latina, se ubica en la posición 32 a nivel mundial y en la sétima entre los países de América Latina, 
no obstante, viene cayendo en este indicador en los últimos tres años. Entre los factores que se consideran determinantes para explicar dicho descenso se encuentran aspectos tales como el salarial, el de participación en la administración pública y el de la violencia de género.

De acuerdo al Reporte Global de Brechas de Género 2009, publicado por el Foro Económico Mundial (Hausmann, Tyson y Zahidi, 2009), en 83 de 132 países se había alcanzado el mismo o mayor número de mujeres en la educación secundaria. En 76 de esos 83 países, el número de mujeres en secundaria era mayor que el de los hombres. En 30 de los 49 países del mundo donde es menor el número de mujeres en secundaria, la matrícula de mujeres es igual o mayor al 90\%. Costa Rica se sitúa entre los 22 países del mundo con mayor presencia femenina en secundaria, con el $7 \%$ más de mujeres que de hombres (gráfico 2).

\section{GRÁFICO 2}

BRECHAS ENTRE HOMBRES Y MUJERES EN EDUCACIÓN, SALUD, OPORTUNIDADES ECONÓMICAS Y EMPODERAMIENTO PÚBLICO

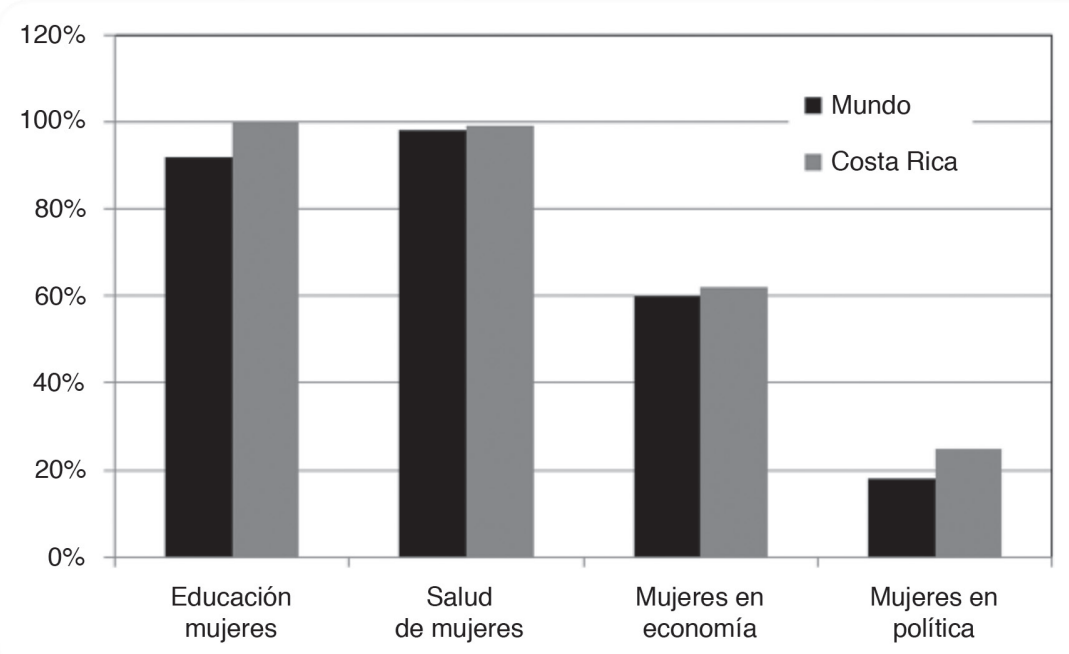

Fuente: Elaboración propia a partir de The Global Gender Gap Report, 2009.

En la educación universitaria, el panorama es todavía más acentuado. Es así como en 1990, se alcanza igualdad o superioridad del número de mujeres en las universidades en 134 países. De ahí que el promedio mundial de participación de mujeres en educación superior es un $19 \%$ mayor a la participación de hombres. En el caso de Costa Rica, este llega a ser un $26 \%$ más. El volumen participativo de las mujeres como profesionales y técnicas en la fuerza de trabajo mundial corresponde, como era de esperar, con su cada vez mayor participación en los sistemas educativos. Por cada 10 hombres técnicos y profesionales, existe una contraparte de 7,4 mujeres.

Sin embargo, esa participación técnica se contrasta fuertemente con su baja participación en las escalas superiores de dirección de las empresas, donde menos de 3 mujeres ocupan puestos de dirección, frente a cada 10 gerentes o directores hombres. A pesar del incremento en su capacidad educativa, la falta de participación femenina en niveles de empresa, donde se deciden las políticas corporativas, termina incidiendo en la menor valoración salarial del trabajo de las mujeres en dichos niveles. El promedio mundial de ingresos de las mujeres 
es globalmente el $52 \%$ con respecto al de los hombres y considerando los salarios percibidos por exactamente el mismo trabajo, las mujeres ganan solo el $66 \%$ de lo que ganan los hombres. No obstante, ante las leyes laborales y regulaciones internacionales, no se ha podido impedir este resultado empírico que arrojan las estadísticas (Hausmann, Tyson y Zahidi, 2009).

Costa Rica es un país que se sitúa en el nivel alto $(0,744)$ en el Índice de Desarrollo Humano del Programa de Naciones Unidas para el Desarrollo (PNuD), ocupando el puesto 69 entre 187 países. El país presenta una aceptable tasa de participación de mujeres en sus sistemas educativos y en la participación de profesionales y técnicos en la fuerza de trabajo; es así como se tienen 12,3 mujeres por cada 10 hombres con enseñanza superior o técnica. Sin embargo, cuando se consideran las diferencias de salario por el mismo empleo, el nivel de ingresos de las mujeres de Costa Rica, está ligeramente por debajo del promedio internacional, ya que las mujeres ganan un promedio del $65 \%$ de lo que ganan los hombres, frente a un $66 \%$, a nivel mundial. En cambio, el nivel de influencia femenina en el país se sitúa, un poco mejor que el promedio internacional; el mismo corresponde al 37\% del nivel de influencia de los hombres contrapuesto al 30\% en el mundo. En este valor se tomó en consideración las mujeres legisladoras y directoras de empresas públicas, donde el país tiene un buen desempeño. Sin embargo, la situación de las mujeres propiamente en la dirección de las empresas se ubica por debajo del promedio internacional, como lo están tam- bién sus niveles salariales (Hausmann, Tyson y Zahidi, 2009).

\section{PARTICIPACIÓN LABORAL FEMENINA}

Durante los últimos veinte años, la participación de la mujer en la fuerza de trabajo ha ido en aumento en la mayoría de los países del mundo. En la década de los 70, la participación femenina en el mercado laboral costarricense era menor al 20\% de las mujeres en edad de trabajar. En los años siguientes, esa situación comenzó a variar de manera sustancial, siendo así que para 1990, su participación alcanzaba un 30,3\%, proporción que aumentó a 35\% en el 2000 y alcanzó su máximo histórico de 43,5\%, en el 2010 .

Esta tendencia creciente de largo plazo en la incorporación al mercado de trabajo por parte de las mujeres, a pesar de no contar con una política explícita al respecto, se puede relacionar con factores como la transición demográfica que se ha expresado en un menor número de hijos por mujer, así como también por el acceso igualitario a la educación, lo cual ha aumentado la disponibilidad de tiempo y ha mejorado las condiciones de las mujeres para acceder a las actividades laborales remuneradas. De igual forma, en las últimas tres décadas se han presentado cambios en la estructura productiva del país, la cual pasa de una economía basada en actividades agropecuarias a una concentrada en los servicios, favoreciendo la incorporación de mano de obra femenina en el mercado laboral. 
GRÁFICO 3

TASAS NETAS DE PARTICIPACIÓN EN TRABAJO REMUNERADO POR SEXO $1950-2010$

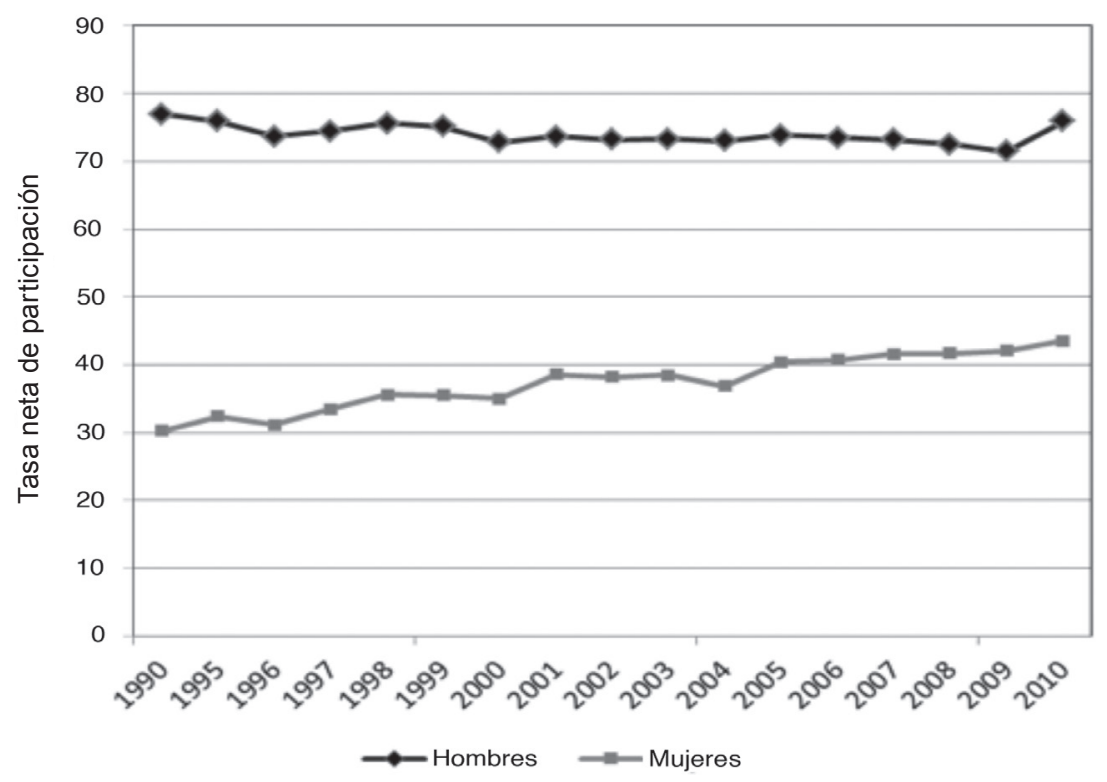

Fuente: Elaboración propia a partir de datos del Instituto Nacional de Estadística y Censos (INEC).

A pesar del alto crecimiento experimentado en la tasa de participación femenina, su oferta laboral constituye solo el $39 \%$ de la oferta laboral total. En el año 2011, las mujeres que representaban una proporción mayor de la población $(50,1 \%)$, representaban solamente el 39\% de la fuerza de trabajo y el $38 \%$ de los ocupados. Sin embargo, es relevante el avance que se observa al comparar estas tasas con las de 1990, pues hace 21 años las mujeres eran solamente el $28 \%$ de la Población Económicamente Activa (PEA) y de la población ocupada (tabla 1). Estos resultados se pueden explicar porque es más frecuente que parte del trabajo económico de las mujeres quede oculto por subdeclaración o porque desempeñan actividades que no se contabilizan en el empleo, como por ejemplo, las actividades primarias para autoconsumo $y$ otras actividades marginales.

TABLA 1

DISTRIBUCIÓN POR SEXO DE LA POBLACIÓN TOTAL FUERZA DE TRABAJO Y POBLACIÓN OCUPADA

COSTA RICA, 2011

\begin{tabular}{|l|c|c|c|c|c|c|}
\hline \multirow{2}{*}{ Sexolaño } & \multicolumn{2}{c|}{1990} & \multicolumn{2}{c|}{2000} & \multicolumn{2}{c|}{2011} \\
\cline { 2 - 8 } & Hombres & Mujeres & Hombres & Mujeres & Hombres & Mujeres \\
\hline Poblacion total & 0.50 & 0.50 & 0.50 & 0.50 & 0.49 & 0.51 \\
\hline Fuerza de trabajo & 0.72 & 0.28 & 0.67 & 0.33 & 0.61 & 0.39 \\
\hline Población ocupada & 0.72 & 0.28 & 0.67 & 0.33 & 0.62 & 0.38 \\
\hline
\end{tabular}

Fuente: Elaboración propia a partir de datos del Instituto Nacional de Estadística y Censos (INEc). 
DESEMPLEO, SUBEMPLEO Y ACCESO A TRABAJOS CALIFICADOS

El crecimiento de la participación de las mujeres en el mercado de trabajo se ha traducido también en un incremento de sus niveles de desempleo y subempleo, más que un aumento en el porcentaje de ocupadas plenas. Asimismo, en muchos casos, su incorporación ha sido en ocupaciones informales y de mala calidad, así como en ocupaciones subvaloradas.

Muestra de lo anterior es que para el 2010, una de cada tres mujeres trabajaba en puestos no calificados, lo cual representa un
5\% más que su contraparte masculina. De igual forma, las mujeres históricamente han presentado una mayor tasa de desempleo abierto $y$ subempleo, como se muestra en la gráfico 4. El desempleo abierto en mujeres $(9,9 \%)$ fue cerca de 3,3 puntos porcentuales mayor al de los hombres durante el 2009, tendencia que se ha mantenido en los últimos 20 años. Esta brecha aumenta al analizar la tasa de subutilización de la mano de obra, tanto visible como invisible. Para el 2009, una de cada cinco mujeres presentaba problemas de inserción al mercado laboral, ya sea por insuficiencia de horas o por percibir un salario menor al establecido por ley.

\section{GRÁFICO 4}

TASAS DE DESEMPLEO ABIERTO Y SUBEMPLEO POR SEXO

COSTA RICA, 1990-2009

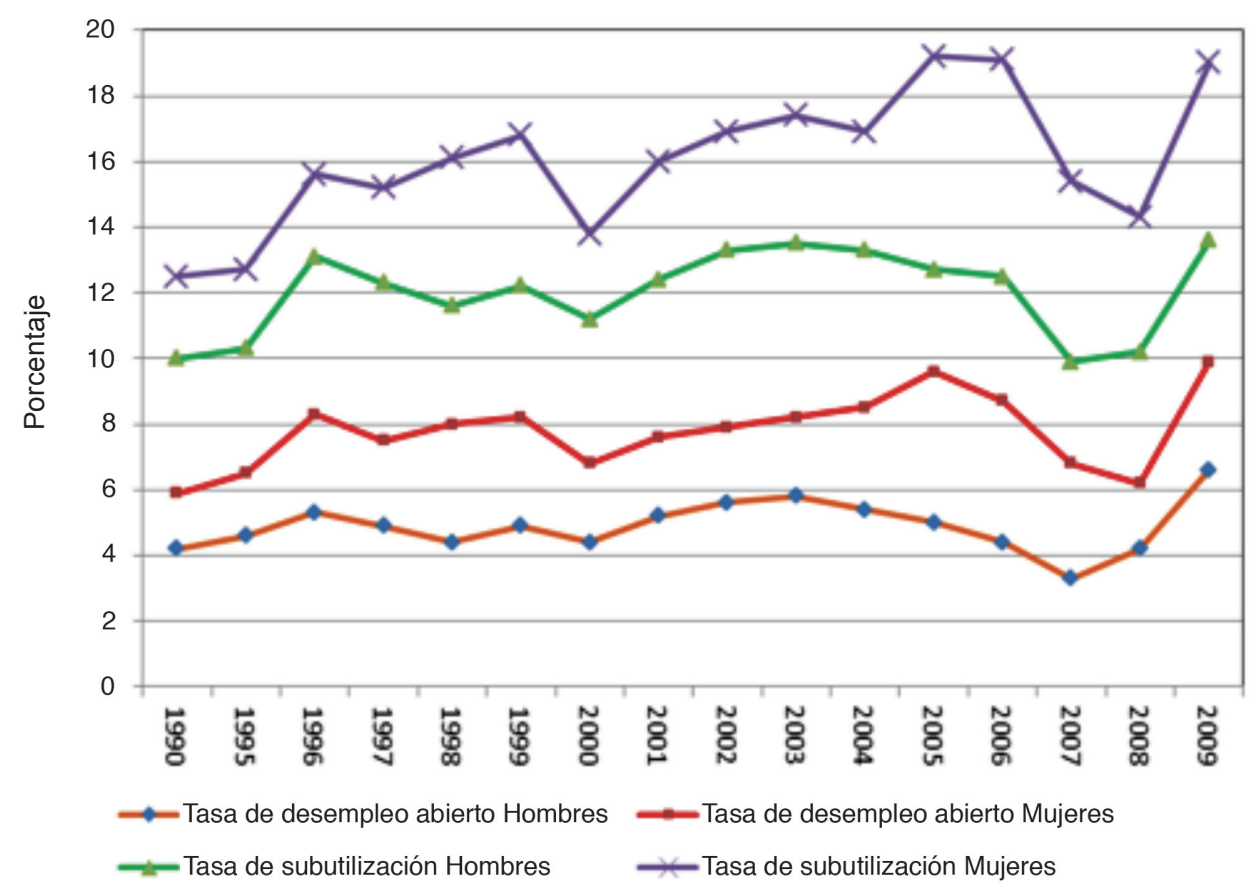

Fuente: Elaboración propia a partir de datos del Instituto Nacional de Estadística y Censos (INEC).

Por otro lado, los esfuerzos para promover un mayor acceso de las mujeres en posiciones de dirección se reflejan en el porcentaje de mujeres con participación dentro dichas actividades. Existe una clara diferencia en la inserción de las mujeres a puestos directivos dentro del sector público y privado. En el primer caso, como se muestra en la tabla 2, la participación de la mujer ha venido aumentando en las últimas dos décadas, pasando del $29,8 \%$ en 1990 
al $44,0 \%$ en 2010 ; mientras que en el sector privado el crecimiento ha sido menor, pasando de $20,7 \%$ en 1990 a $23,8 \%$ en 2010.

TABLA 2

PORCENTAJE MUJERES OCUPADAS COMO DIRECTORAS DEL TOTAL DE PERSONAS OCUPADAS EN ESOS PUESTOS COSTA RICA, 1990-2010

\begin{tabular}{|c|c|c|c|}
\hline AÑO & TOTAL PAÍS & $\begin{array}{l}\text { EN SECTOR } \\
\text { PÚBLICO }\end{array}$ & $\begin{array}{c}\text { EN SECTOR } \\
\text { PRIVADO }\end{array}$ \\
\hline 1990 & 23,3 & 29,8 & 20,7 \\
\hline 1995 & 23,4 & 27,6 & 21,8 \\
\hline 1996 & 26,7 & 39,3 & 22,7 \\
\hline 1997 & 27,5 & 35,7 & 24,6 \\
\hline 1998 & 30,1 & 43,7 & 26,0 \\
\hline 1999 & 30,6 & 33,1 & 30,0 \\
\hline 2000 & 30,0 & 34,5 & 28,7 \\
\hline 2001 & 25,4 & 38,1 & 20,3 \\
\hline 2002 & 26,1 & 42,8 & 20,9 \\
\hline 2003 & 29,1 & 46,2 & 23,3 \\
\hline 2004 & 26,2 & 42,6 & 20,6 \\
\hline 2005 & 24,9 & 38,9 & 19,0 \\
\hline 2006 & 29,9 & 53,3 & 21,5 \\
\hline 2007 & 27,0 & 47,4 & 19,3 \\
\hline 2008 & 30,4 & 49,7 & 22,1 \\
\hline 2009 & 30,4 & 46,4 & 23,3 \\
\hline 2010 & 29,7 & 44,1 & 23,8 \\
\hline
\end{tabular}

Fuente: Elaboración propia a partir de datos del Instituto Nacional de Estadística y Censos (INEC).

Durante el período 2002-2011, el empleo asalariado de las mujeres ha mostrado una tendencia creciente, al pasar del $68 \%$ al $76 \%$ en el empleo total. En contraposición se han reducido las categorías de cuenta propia y los trabajadores no remunerados. Al desagregar por sexo la categoría ocupacional, se observan diferencias relevantes (tabla 3 ). Por ejemplo, en el año 2011, las mujeres asalariadas representan el 78,9\% (en 2002 eran el 70,8\%), las cuenta propia un $17,2 \%$ (representaban un $20,3 \%$ en 2002), los patronos un 2,2\% y las no remuneradas el 1,7\%. En los hombres la distribución es levemente distinta: para el 2011, los asalariados constituyen el 74,2\% (constituían el $67 \%$ en $2002)$, los cuenta propia el 20\% (21\% en 2002), los patronos el $4,8 \%$ y los no remunerados el $1 \%$.

TABLA 3

DISTRIBUCIÓN DE LA POBLACIÓN OCUPADA POR CATEGORÍA OCUPACIONAL SEGÚN SEXO COSTA RICA, 2011

\begin{tabular}{l|c|c}
\hline Categoria ocupacional / sexo & Hombres & Mujeres \\
\hline Asalariada total & 74,2 & 78,9 \\
\hline Asalariada de empresas e instituciones & 73,3 & 60,6 \\
\hline Asalariada de hogares privados & 1,0 & 18,3 \\
\hline Auxiliares no remunerados & 1,0 & 1,7 \\
\hline Empleadora & 4,8 & 2,2 \\
\hline Cuenta Propia & 20,0 & 17,2 \\
\hline
\end{tabular}

Fuente: Elaboración propia a partir de datos del Instituto Nacional de Estadística y Censos (INEC).

La presencia de mujeres en la categoría de trabajadores por cuenta propia y en los trabajos no remunerados podría estar reflejando una precaria inserción laboral, pues estas categorías de empleo son altamente vulnerables $y$ corresponden a sectores de baja productividad, en los que predomina la economía de subsistencia. Para el año 2000, de acuerdo a un estudio realizado por Trejos (2003), sobre informalidad a nivel nacional, las mujeres constituían cerca del 35\% de la población ocupada en el sector informal, mientras en las actividades no agrícolas representaban un $40 \%$ y en los micronegocios un $38 \%$. Dentro de este último rubro el peso de las mujeres aumenta, especialmente en el autoempleo, así mismo, su participación crece conforme menos productivo sea el establecimiento. Estas características de inserción sugieren que el mercado de trabajo impone restricciones de acceso a las mujeres, particularmente, a las de mayor edad y menor calificación o que solo 
pueden incorporarse de manera parcial, para quienes el trabajo independiente se torna casi su única opción de generar ingresos para sobrevivir (Trejos, 2000).

ESCOLARIDAD, SALARIOS, POBREZA Y

COBERTURA DE SALUD

El grado de escolaridad del conjunto de la fuerza de trabajo aumentó significativamente en las últimas dos décadas, no obstante, este aumento fue más intenso en el caso de las mujeres. Las mujeres que tienen mayor nivel educativo disponen de más y mejores oportunidades de empleo, en comparación con las que tienen menos años de escolaridad $y$ sus tasas de participación y de ocupación son significativamente mayores, así como lo es su presencia en las ocupaciones formales. Sin embargo, esa relación no se mantiene si se comparan hombres y mujeres. Las mujeres necesitan un número de años de estudio significativamente mayor para acceder a las mismas oportunidades de empleo y condiciones de trabajo respecto a los hombres (tabla 4). 


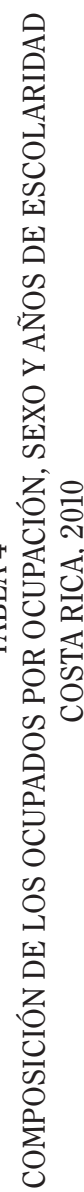

\begin{tabular}{|c|c|c|c|c|c|c|c|c|c|c|}
\hline \multicolumn{2}{|l|}{ 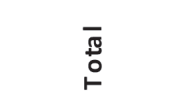 } & $\begin{array}{l}0 \\
0 \\
0 \\
0 \\
-1\end{array}$ & $\begin{array}{l}0 \\
0 \\
0 \\
0 \\
-1\end{array}$ & $\begin{array}{l}\circ \\
\text { oे } \\
\text { ¿े } \\
\end{array}$ & $\begin{array}{l}\text { ठे } \\
\text { ठे } \\
\text {-े }\end{array}$ & $\begin{array}{l}0 \\
0 \\
0 \\
0 \\
-1\end{array}$ & $\begin{array}{l}0 \\
0 \\
0 \\
0 \\
-1\end{array}$ & $\begin{array}{l}\circ \\
\text { oे } \\
\text { ○े } \\
\end{array}$ & $\begin{array}{l}0 \\
0 \\
0 \\
0 \\
-1\end{array}$ & $\begin{array}{l}\circ \\
\text { oे } \\
\text { ¿े } \\
\end{array}$ \\
\hline \multirow{2}{*}{ 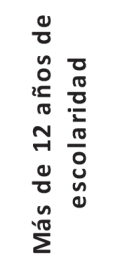 } & 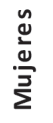 & $\begin{array}{l}\text { 今े } \\
\text { जे }\end{array}$ & 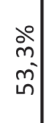 & $\begin{array}{l}\stackrel{0}{\hat{0}} \\
6 \\
-1\end{array}$ & $\begin{array}{l}\stackrel{0}{7} \\
\stackrel{-}{n}\end{array}$ & $\begin{array}{c}\stackrel{0}{े} \\
\dot{\nabla}\end{array}$ & $\begin{array}{l}\stackrel{0}{2} \\
0 \\
0\end{array}$ & $\begin{array}{l}\stackrel{0}{-} \\
-i\end{array}$ & $\begin{array}{l}\stackrel{0}{2} \\
\vdots\end{array}$ & $\begin{array}{l}\stackrel{0}{\rightarrow} \\
-1\end{array}$ \\
\hline & 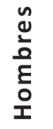 & 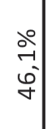 & $\begin{array}{l}\text { वे } \\
\vec{y} \\
\dot{y}\end{array}$ & $\begin{array}{l}\text { 今े } \\
\text { जे }\end{array}$ & $\begin{array}{l}\text { 今े } \\
\text { on } \\
\text { - }\end{array}$ & $\begin{array}{l}\text { ठें } \\
\text { ले }\end{array}$ & ৯े & $\begin{array}{l}\circ \\
\infty \\
\sim \\
\sim\end{array}$ & $\begin{array}{l}\circ \\
0 \\
\text { m. }\end{array}$ & $\begin{array}{l}\grave{0} \\
0 \\
0\end{array}$ \\
\hline \multirow{2}{*}{ 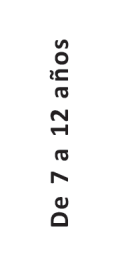 } & 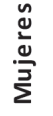 & $\begin{array}{l}\stackrel{0}{i} \\
\stackrel{2}{1}\end{array}$ & 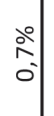 & $\begin{array}{l}\text { خे } \\
\text { जी }\end{array}$ & $\begin{array}{l}\grave{0} \\
\text { जी }\end{array}$ & 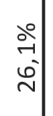 & $\begin{array}{l}\stackrel{0}{0} \\
\stackrel{\sim}{n}\end{array}$ & خे & $\begin{array}{l}\stackrel{0}{7} \\
6\end{array}$ & $\begin{array}{l}\text { ১े } \\
\text { ma } \\
\text { - }\end{array}$ \\
\hline & 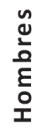 & $\begin{array}{l}\text { ○े } \\
-1 \\
-1\end{array}$ & $\begin{array}{l}\stackrel{0}{-} \\
-1\end{array}$ & $\begin{array}{c}\text { के } \\
\vec{m}\end{array}$ & $\begin{array}{l}\grave{0} \\
0 \\
0\end{array}$ & $\begin{array}{l}\grave{0} \\
\stackrel{\sim}{0} \\
\stackrel{n}{2}\end{array}$ & $\begin{array}{l}0 \\
0 \\
0 \\
-1\end{array}$ & $\begin{array}{l}\stackrel{0}{0} \\
\text { oे }\end{array}$ & $\begin{array}{l}\stackrel{0}{0} \\
\infty \\
m\end{array}$ & $\begin{array}{l}\stackrel{0}{\hat{2}} \\
6 \\
-1\end{array}$ \\
\hline \multirow{2}{*}{ 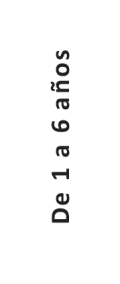 } & 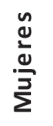 & $\begin{array}{l}\text { مे } \\
-i\end{array}$ & $\begin{array}{l}\text { वें } \\
0\end{array}$ & $\begin{array}{l}\stackrel{\circ}{2} \\
-1\end{array}$ & $\begin{array}{l}\circ \\
0 \\
\text { m. }\end{array}$ & $\begin{array}{l}\text { 今े } \\
\text { ○े }\end{array}$ & วัْ & $\begin{array}{l}\stackrel{0}{0} \\
\infty \\
\infty\end{array}$ & $\begin{array}{l}\text { 今े } \\
\text { i }\end{array}$ & 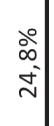 \\
\hline & 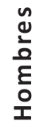 & $\begin{array}{c}\stackrel{\circ}{\tilde{m}} \\
6\end{array}$ & $\begin{array}{l}0 \\
\infty \\
0 \\
0\end{array}$ & $\begin{array}{l}\stackrel{0}{-} \\
\stackrel{-}{-}\end{array}$ & 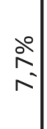 & $\begin{array}{l}\text { 今े } \\
\text { ○े }\end{array}$ & $\begin{array}{l}0 \\
0 \\
0 \\
0\end{array}$ & $\begin{array}{l}\stackrel{0}{0} \\
0 \\
m\end{array}$ & $\begin{array}{l}\grave{0} \\
0 \\
y\end{array}$ & $\begin{array}{l}\stackrel{0}{1} \\
\hat{n}\end{array}$ \\
\hline \multirow{2}{*}{ 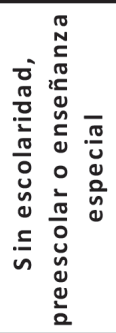 } & $\frac{\varrho}{\frac{\tilde{U}}{\tilde{e}}}$ & $\begin{array}{l}\text { 今े } \\
0\end{array}$ & $\begin{array}{l}\text { 今े } \\
0 \\
0\end{array}$ & $\begin{array}{l}\circ \\
0 \\
0\end{array}$ & $\begin{array}{l}\stackrel{0}{0} \\
0\end{array}$ & $\stackrel{\stackrel{े}{े}}{\rightarrow-1}$ & 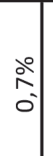 & $\begin{array}{l}\stackrel{0}{0} \\
\text { o }\end{array}$ & $\begin{array}{l}\stackrel{0}{2} \\
0 \\
0\end{array}$ & $\underset{\stackrel{े}{े}}{\stackrel{\circ}{-}}$ \\
\hline & $\begin{array}{l}\text { ऐo } \\
\text { है } \\
\text { 오 }\end{array}$ & $\begin{array}{l}\stackrel{0}{-} \\
0\end{array}$ & $\begin{array}{l}\text { वे| } \\
\text { - }\end{array}$ & $\begin{array}{l}\text { 今े } \\
\text { ஸे }\end{array}$ & $\begin{array}{l}\stackrel{\circ}{\circ} \\
0^{\circ}\end{array}$ & $\begin{array}{l}\circ \\
0 \\
0 \\
0\end{array}$ & $\begin{array}{l}\stackrel{\circ}{7} \\
6 \\
6\end{array}$ & 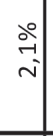 & $\begin{array}{l}\stackrel{\circ}{1} \\
\stackrel{i}{1}\end{array}$ & $\begin{array}{l}\stackrel{\circ}{0} \\
\stackrel{+}{0}\end{array}$ \\
\hline 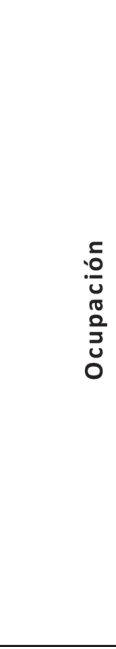 & & 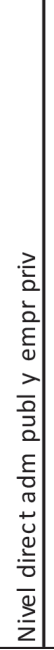 & 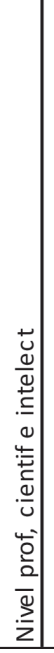 & 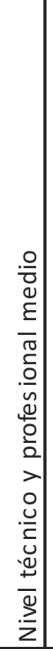 & 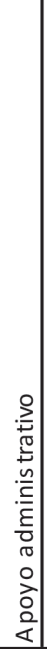 & 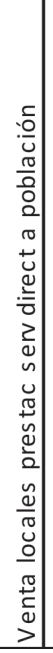 & 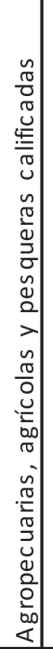 & 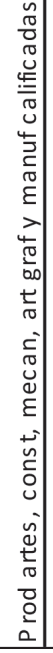 & 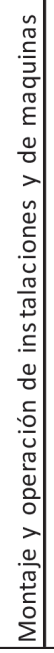 & 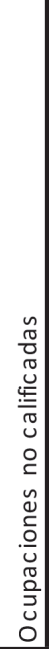 \\
\hline
\end{tabular}


De igual forma, la mayor educación no implica necesariamente que el ingreso promedio mensual de las mujeres se aproxime al de los hombres. Al considerar la evolución del ingreso promedio mensual de los(as) ocupados(as), se observa que la brecha de ingresos entre hombres y mujeres persiste. Según datos del año 2000, los salarios de las mujeres corresponden a $90 \%$ del salario de los hombres, valor que disminuye al $83 \%$ en el 2007 y alcanza $91 \%$ en 2010 (gráfico 5).

\section{GRÁFICO 5}

BRECHA DE GÉNERO EN EL SALARIO PROMEDIO MENSUAL

(MUJERES/HOMBRES)

COSTA RICA, 2000-2010

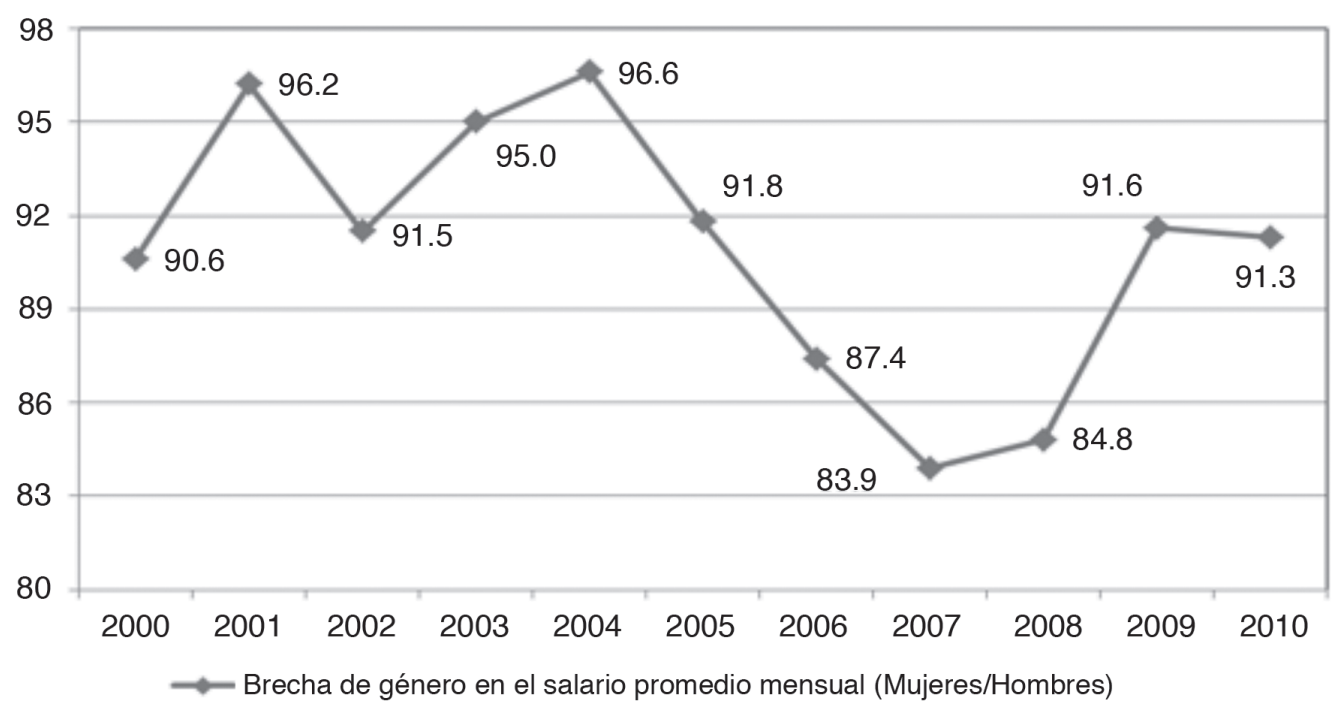

Fuente: Elaboración propia a partir de datos del Instituto Nacional de Estadística y Censos (INEc).

Por otro lado, el gráfico 6 muestra la diferencia salarial por sexo según el sector institucional. Es así como en 2008, los hombres empleados en el sector privado ganaban en promedio cerca de $36 \%$ más que las mujeres, lo mismo sucede en el sector público, aunque en menor magnitud, la diferencia era cercana al $12 \%$. 


\section{GRÁFICO 6}

DIFERENCIA SALARIAL (\%) POR SEXO Y SECTOR INSTITUCIONAL

INGRESO PROMEDIO MENSUAL REAL

COSTA RICA, JULIO 2009

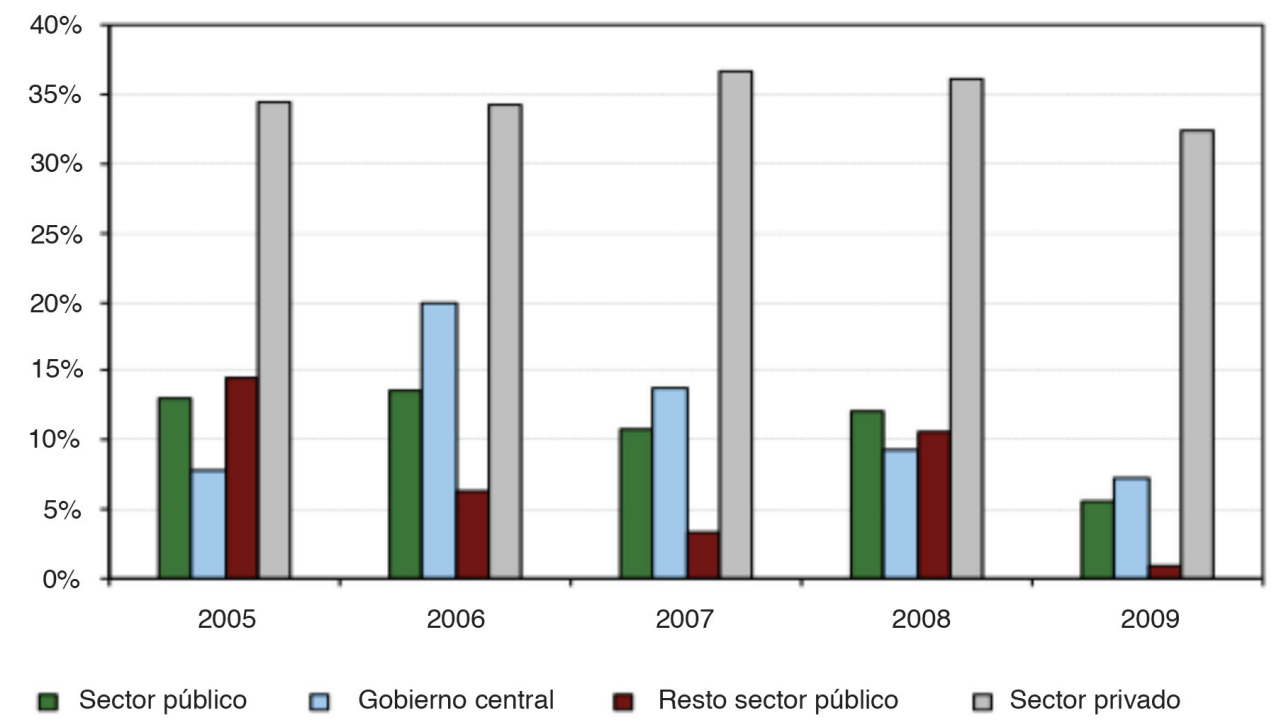

Fuente: Encuesta de Hogares y Propósitos Múltiples del Instituto Nacional de Estadística y Censos (INEC).

Los datos para el año 1990, indican que el porcentaje de pobreza extrema era de un $6,4 \%$ en los hogares con jefatura masculina, mientras que en el caso de los hogares con je- fatura femenina, ese porcentaje se ubicó en el $10,0 \%$. En 2010, la pobreza extrema femenina alcanzó el 7,4\% y la masculina fue del 5,3\% (tabla 5). 
TABLA 5

PORCENTAJE DE HOGARES POBRES SEGÚN JEFATURA

COSTA RICA, 1990-2010

\begin{tabular}{|c|c|c|c|c|c|c|}
\hline & \multicolumn{5}{|c|}{ Jefaturas de hogar } \\
\cline { 2 - 7 } Año & $\begin{array}{c}\text { Porcentaje } \\
\text { jefes } \\
\text { pobres }\end{array}$ & $\begin{array}{c}\text { Porcentaje } \\
\text { jefas } \\
\text { pobres }\end{array}$ & $\begin{array}{c}\text { Diferencia } \\
\text { jefes-jefas } \\
\text { pobres }\end{array}$ & $\begin{array}{c}\text { Porcentaje } \\
\text { jefes en } \\
\text { ex trema } \\
\text { pobreza }\end{array}$ & $\begin{array}{c}\text { Porcentaje } \\
\text { jefas en } \\
\text { ex trema } \\
\text { pobreza }\end{array}$ & $\begin{array}{c}\text { Diferencia } \\
\text { jefes-jefas s ex tre ma } \\
\text { pobreza }\end{array}$ \\
\hline $\mathbf{1 9 9 0}$ & 20,5 & 23,7 & $-3,2$ & 6,4 & 10,0 & $-3,6$ \\
\hline $\mathbf{1 9 9 5}$ & 15,7 & 22,4 & $-6,7$ & 4,7 & 7,2 & $-2,5$ \\
\hline $\mathbf{1 9 9 6}$ & 17,1 & 22,9 & $-5,8$ & 5,0 & 9,0 & $-4,0$ \\
\hline $\mathbf{1 9 9 7}$ & 16,2 & 22,2 & $-6,0$ & 4,2 & 7,0 & $-2,8$ \\
\hline $\mathbf{1 9 9 8}$ & 15,5 & 21,2 & $-5,7$ & 3,7 & 7,2 & $-3,5$ \\
\hline $\mathbf{1 9 9 9}$ & 15,3 & 25,2 & $-9,9$ & 4,5 & 9,7 & $-5,2$ \\
\hline $\mathbf{2 0 0 0}$ & 16,0 & 23,8 & $-7,8$ & 4,3 & 8,4 & $-4,2$ \\
\hline $\mathbf{2 0 0 1}$ & 15,1 & 21,0 & $-5,9$ & 4,1 & 7,1 & $-3,0$ \\
\hline $\mathbf{2 0 0 2}$ & 16,0 & 20,5 & $-4,5$ & 4,1 & 6,5 & $-2,4$ \\
\hline $\mathbf{2 0 0 3}$ & 14,5 & 20,4 & $-5,9$ & 3,8 & 6,3 & $-2,5$ \\
\hline $\mathbf{2 0 0 4}$ & 17,3 & 24,0 & $-6,7$ & 4,2 & 7,0 & $-2,8$ \\
\hline $\mathbf{2 0 0 5}$ & 17,8 & 24,1 & $-6,3$ & 4,0 & 8,2 & $-4,2$ \\
\hline $\mathbf{2 0 0 6}$ & 16,3 & 23,9 & $-7,6$ & 3,8 & 7,7 & $-3,9$ \\
\hline $\mathbf{2 0 0 7}$ & 14,1 & 19,0 & $-4,9$ & 2,4 & 4,5 & $-2,1$ \\
\hline $\mathbf{2 0 0 8}$ & 14,5 & 18,9 & $-4,4$ & 2,2 & 5,2 & $-3,0$ \\
\hline $\mathbf{2 0 0 9}$ & 15,7 & 20,7 & $-5,0$ & 3,0 & 5,9 & $-2,9$ \\
\hline $\mathbf{2 0 1 0}$ & 15,2 & 15,4 & $-0,2$ & 5,3 & 7,4 & $-2,1$ \\
\hline
\end{tabular}

Fuente: Encuesta de Hogares y Propósitos Múltiples del Instituto Nacional de Estadística y Censos (INEc).

La pobreza extrema en jefas de hogar ha disminuido en los últimos 5 años; no obstante, la pobreza total en jefas de hogar se ha mantenido en el orden del $20 \%$ durante las últimas dos décadas, cerca de 4 puntos porcentuales en promedio por encima de la pobreza en jefes de hogar (tabla 5). Esta situación no sólo limita las posibilidades de un importante porcentaje de la población femenina del país de acceder a mejores condiciones de vida, sino que además condiciona las posibilidades de los dependientes del hogar, en su gran mayoría menores de edad, a tener una vida sin carencias (Arias, 2006).
Tratando de hacer una estimación de la situación de las mujeres y hombres no ligada a la definición de pobreza, se calcula el porcentaje de la población de 15 años y más sin ingresos propios. Los datos muestran una tendencia a la reducción de la brecha, sin embargo, la diferencia entre mujeres $y$ hombres sigue siendo muy significativa. Para el año 2000, la diferencia era de 37 puntos porcentuales y para el año 2009, de 25 puntos.

En el año 2009, el 41,5\% de las mujeres no contaba con ingresos propios versus un $16,8 \%$ de los hombres (gráfico 7). 
GRÁFICO 7

PORCENTAJE DE LA POBLACIÓN DE 15 AÑOS Y MÁS

SIN INGRESOS PROPIOS, POR SEXO

COSTA RICA, 2000-2009

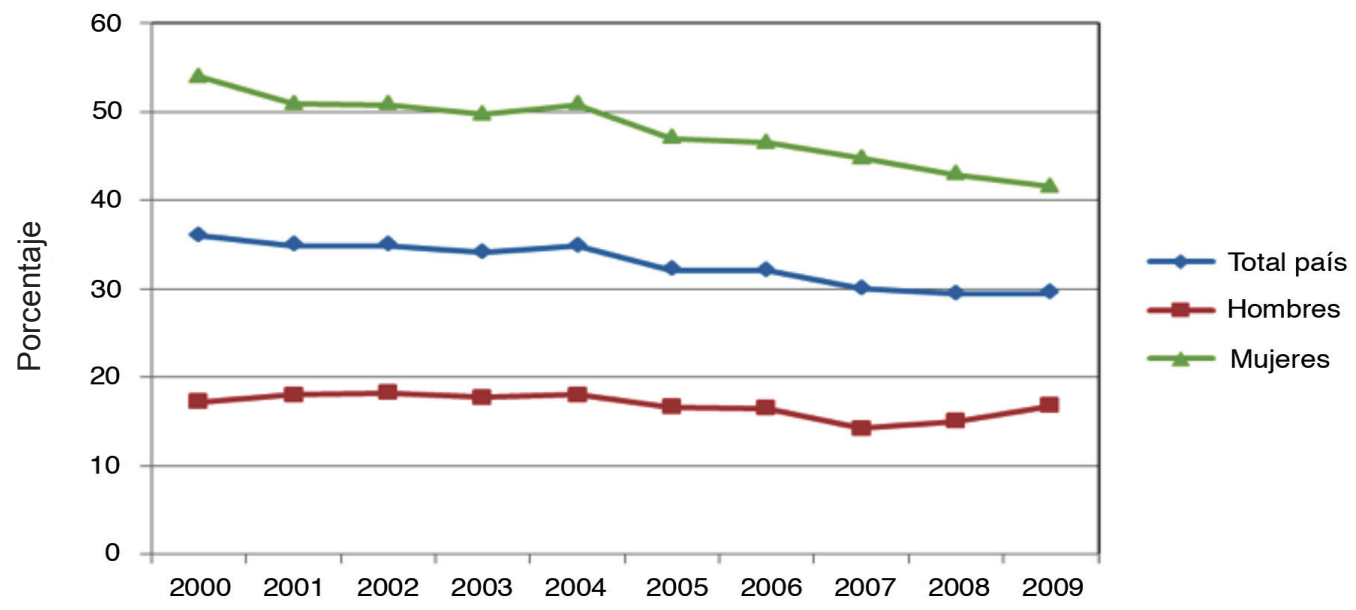

Fuente: Encuesta de Hogares y Propósitos Múltiples del Instituto Nacional de Estadística y Censos (INEc).

Además de la baja remuneración percibida por las mujeres trabajadoras por cuenta propia, en esta población se registran bajos niveles de cobertura de la seguridad social. Por ejemplo, en el 2009, el 15\% de las mu- jeres trabajadoras cuenta propia estaban afiliadas a algún seguro de salud, lo cual refleja uno de los porcentajes más altos durante el período (gráfico 8).

\section{GRÁFICO 8}

PORCENTAJE DE MUJERES TRABAJADORAS CUENTA PROPIA CON SEGURO DE SALUD COSTA RICA, 1990-2009

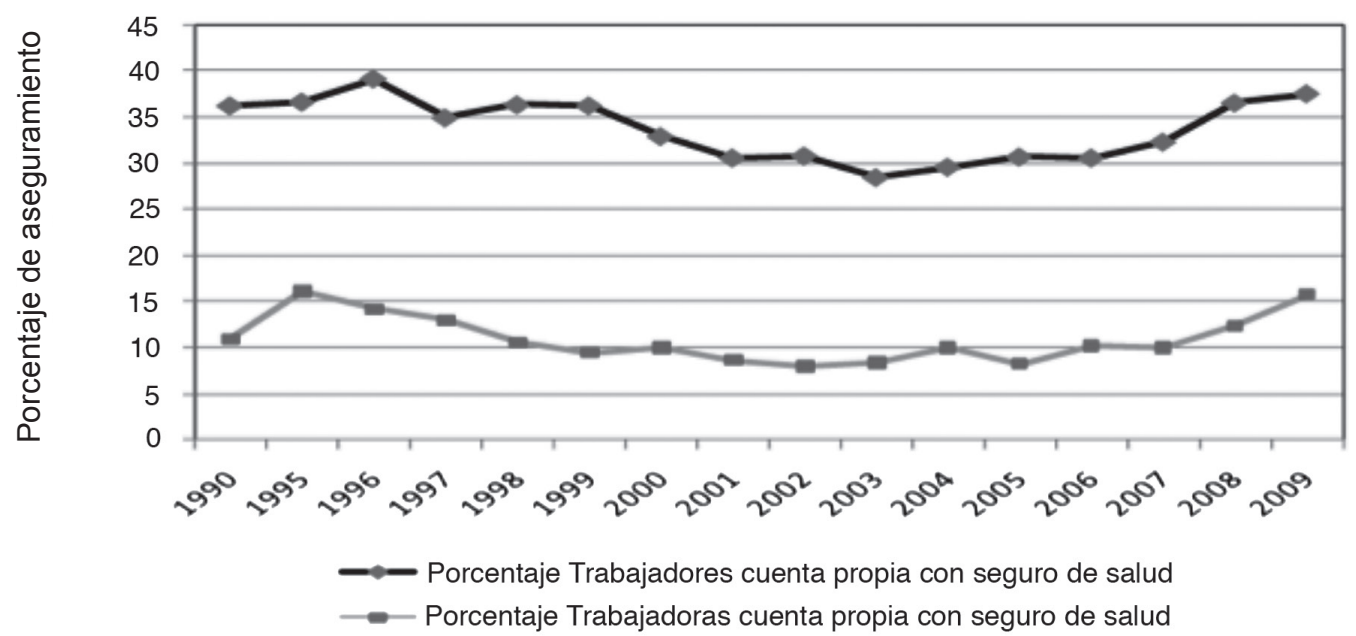

Fuente: Encuesta de Hogares y Propósitos Múltiples del Instituto Nacional de Estadística y Censos (INEc). 
PARTICIPACIÓN FEMENINA EN EL SECTOR EMPRESARIAL

El tema de la igualdad de la mujer en lo productivo, ha pasado de una discusión formal de derechos humanos hacia una visión económica de competitividad y eficiencia. El contraste patente entre los avances en la capacidad educativa y profesional de las mujeres y su desigual participación en los niveles superiores de la administración de las empresas, plantea el tema del avance social y económico de las mujeres como un tema de aprovechamiento competitivo de sus capacidades, más allá de la superación de contrastes entre la igualdad jurí- dica formal $y$ la verificable desigualdad real de oportunidades.

El análisis de las últimas dos décadas muestra que se produjo un aumento en el porcentaje de mujeres patronas con 1 a 9 empleados contratados respecto a los hombres, al incrementarse de 9,6\% a 23,1\% de 1990 al 2001. Esto es particularmente evidente en establecimientos de 1 a 4 ocupados localizados en la zona urbana. Muestra de lo anterior es que en el país durante el 2010, el porcentaje de mujeres patronas no supera el $20 \%$ del total de patronos del país $y$ este porcentaje disminuye conforme aumenta el número de empleados de la empresa (tabla 6). 


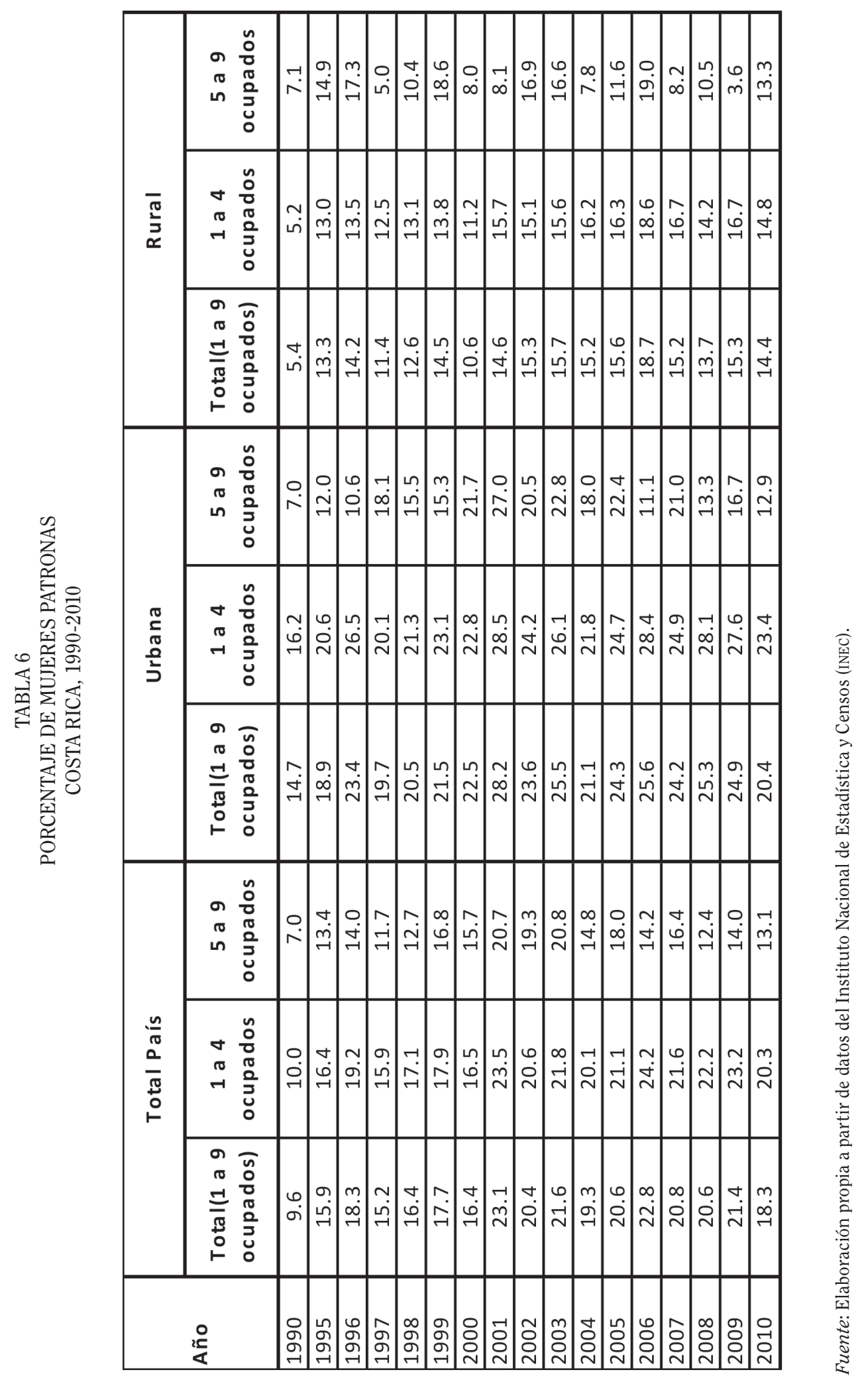


La mayor participación de las mujeres patronas en locales de 1 a 4 ocupados, tanto en zonas urbanas como rurales, es un aspecto desventajoso para este sector, ya que ese tipo de actividades están asociadas al autoempleo de subsistencia y al trabajo familiar de menor productividad, lo cual establece dificultades para ser beneficiario de recursos indispensables para los procesos productivos de calidad, como asistencia técnica, crédito y tierra, entre otros. De igual forma, este tipo de actividades aumentan la posibilidad de las mujeres de estar desprotegidas en el tanto no estén cubiertas por el seguro social de forma directa. Esta situación está asociada al trabajo de carácter temporal o informal en actividades económicas no reguladas, lo cual a su vez afecta negativamente los salarios percibidos por actividades de cuenta propia o por subcontratación, dos formas características del empleo femenino.

De lo expuesto en esta sección se concluye que en las últimas décadas, las desigualdades socioeconómicas de género han tendido a disminuir relativamente, debido entre otras razones a un mayor acceso a la educación, menor fecundidad $y$ mejores oportunidades de inserción en el mercado laboral para las mujeres. Sin embargo, en la actualidad sigue existiendo diferencia en la forma en que los hombres y las mujeres se incorporan a diferentes actividades, ya sean productivas, laborales, sociales y políticas.

\section{CONCLUSIONES}

Las expectativas de alcanzar avances con la consolidación de la cultura de derechos e institucionalidad democrática y el avance educativo de la mujer, parecen no haber sido suficientes para erradicar desigualdades de inserción en la vida tanto económica como política; así como en cuanto al acceso y propiedad de activos productivos. De tal forma, las capacidades derivadas de una mayor competencia educativa en las mujeres no han sido suficientes para lograr avances correspondientes a la reducción de las desigualdades todavía persistentes en los distintos ámbitos como el económico, político, social y cultural en Costa Rica.

Algunos factores que explican la desigualdad de género se encuentran más asociados a la falta de reconocimiento del trabajo de las mujeres, condiciones desfavorables para entrar al mercado laboral y segmentación laboral, discriminación en algunos aspectos de educación (en particular en el tema de especialización disciplinaria), violencia contra las mujeres, dificultades para derribar las normas tradicionales y prácticas culturales de género, la escasez de recursos para las iniciativas de mujeres y falta de "ideologías de género efectivas" (Programa Estado de la Nación, 2005).

De igual forma, el incremento de la participación femenina en el mercado de trabajo en las últimas décadas no siempre se ha dado en condiciones de calidad, ni tampoco al margen de crecientes tensiones entre el trabajo remunerado $y$ no remunerado, o entre la vida laboral y el ámbito de lo doméstico. Aún cuando posean mejores grados de calificación que los hombres, las mujeres enfrentan con mayor frecuencia problemas de desempleo, subempleo, brechas de ingresos $y$ acceso a recursos productivos, que afectan sus derechos y oportunidades de desarrollo personal y profesional. Las persistentes condiciones de discriminación generan además, empobrecimiento e incrementan la desigualdad, por cuanto muchas mujeres se insertan en jornadas parciales o de medio tiempo que no son reconocidas formalmente.

Con respecto a las condiciones socioeconómicas de los hogares encabezados por mujeres, los autores Monge y González (2008) proponen que es probable que en este grupo se presente una mayor incidencia de pobreza principalmente por cuatro razones: 1) porque tienen menos capacidad de generar ingreso que los hogares encabezados por hombres; 2) porque las mujeres que encabezan un hogar por lo general, tienen más edad que sus contrapartes masculinos lo cual significa un problema mayor para insertarse en el mercado laboral; 3) en los hogares encabezados por mujeres hay más dependencia de 'otros' ingresos que no pueden garantizarse y 4) las jefas de hogar tienen niveles más bajos de educación que sus contrapartes masculinos. La vulnerabilidad de los hogares encabezados por mujeres, 
también aumenta con el número de niños en el hogar.

La feminización de la pobreza también tiene un impacto negativo sobre las posibilidades de desarrollo de los menores de edad que se encuentran en condiciones de vulnerabilidad socioeconómica. Un impacto de esta desigualdad se asocia con las habilidades y la motivación que comienzan a desarrollarse en la edad temprana y en la que influye el entorno de aprendizaje en el hogar, la escuela y la comunidad. La segregación residencial puede atrapar a los niños de familias pobres en niveles muy bajos de escolaridad debido a la falta de financiamiento para las escuelas en las comunidades pobres $y$ a factores sociológicos como externalidades en el aprendizaje en grupo y a la ausencia o debilidad de un marco de valores y reglas claras a seguir, lo cual contribuye a perpetuar círculos viciosos de pobreza y desigualdad (Muñoz, 2006).

Las políticas públicas afectan de manera diferente a mujeres $y$ hombres, ya que tienen necesidades distintas $y$ acceden de manera diferente a los recursos y a su control. Por esto se hace necesario que los planes $y$ políticas públicas se diseñen tomando en cuenta estas diferencias de género. La creación de nuevas oportunidades de empleo de calidad tiene que estar asociada al desarrollo de condiciones laborales propicias que fomenten el potencial laboral de las mujeres mediante su participación activa en el mercado de trabajo contribuyendo con su bienestar personal y la calidad de vida de sus familias. El mejoramiento o la implementación de las políticas socio-laborales de igualdad de oportunidades para eliminar las situaciones de discriminación que afectan a las mujeres a nivel ocupacional, es crucial para promover una mejor inserción al mercado laboral, con mejores calificaciones de su fuerza de trabajo $y$ por tanto, con mejores remuneraciones salariales. Lo anterior propicia también el mejoramiento de las capacidades productivas de las mujeres, no solo para aspirar a posiciones de trabajo más calificadas sino también para convertirse en emprendedoras de sus propios negocios.
BIBLIOGRAFÍA

LIBROS

Alfaro, María Cecilia. "El género y nuestra historia personal". Develando el género: elementos conceptuales básicos para entender la equidad. Serie hacia la equidad. San José, Costa Rica: Unión Mundial para la Naturaleza-Fundación Arias para la Paz-El Progreso Humano, 1999.

Arias, Rafael y Muñoz, Juan. "Hacia una reconceptualización de la política social: revisión del debate teórico más reciente". Revista de Ciencias Económicas 2 (26). San José, Costa Rica. Universidad de Costa Rica, julio-diciembre 2008: 157181.

Arias, Rafael. Iniquidades socioeconómicas en Costa Rica. San José, Costa Rica: United Nations Children's Fund-unicef, 2006.

Arias, Rafael; Sánchez, Rafael y Sánchez, Leonardo. "Transformación productiva $y$ desigualdad en Costa Rica". Revista de Ciencias Económicas 1 (29). San José, Costa Rica. Universidad de Costa Rica, 2011: 59-95.

Asamblea Legislativa de la República de Costa Rica. "Ley Nro. 7801 del Instituto Nacional de las Mujeres". La Gaceta 94. San José, Costa Rica. 18 de mayo de 1998.

Comisión Económica para América Latina $y$ el Caribe.cepal, Oficina del Alto Comisionado para los derechos humanos-oACDH y Committee on the Elimination of Discrimination against Women-cedaw. Compilación de observaciones finales del Comité para la Eliminación de la Discriminación contra la Mujer sobre países de América Latina $y$ el Caribe (1982-2005). Santiago de Chile, Chile. 2005.

Fraser, Nancy. Social justice in the age of identity politics: redistribution, recognition and participation. The Tanner lectures on human values. California, eeuu: Stanford University, 1996. 
Hausmann, Ricardo; Tyson, Laura y Zahidi, Saadia. The Global Gender Report. Geneva, Suiza: World Economic Forum, 2009.

Instituto Nacional de las Mujeres-inamu. "Informe Nacional Costa Rica". Ponencia XI Conferencia regional sobre la mujer de América Latina y el Caribe. Brasilia, Brasil. Del 13 al 16 de julio de 2010.

Instituto Nacional de las Mujeres-inamu. Plan de Acción. Política Nacional para la Igualdad y Equidad de Género. Versión preliminar. San José, Costa Rica: Procesos y United Nations Population Fund-unFPa, 2007b.

Instituto Nacional de las Mujeres-inamu. Política Nacional para la Igualdad y Equidad de Género 2007-2017. 2 ed. San José, Costa Rica: Instituto Nacional de las Mujeres, 2007a.

Monge, Guillermo y González, Gladys. "Las experiencias centroamericanas de presupuestos de género en el nivel nacional: un análisis crítico". La Agenda Económica de las Mujeres (AGEM). San José, Costa Rica: Fondo de Desarrollo de las Naciones Unidas para la Mujer -unifEm/ Programa de las Naciones Unidas para el Desarrollo-pnud, 2008.

Mora, Luis (coord.). Igualdad y equidad de género: aproximación teóricoconceptual 1. México: Fondo de Población de Naciones Unidas-unfPa, 2006

Muñoz, Leda (coord.). V Estado de los Derechos de la Niñez y la Adolescencia en Costa Rica, 2005. San José, Costa Rica: Ediciones Sanabria, 2006.

Organización Panamericana de la Salud. La economía invisible y las desigualdades de género. La importancia de medir y valorar el trabajo no remunerado. Washington DC, Eeuu: Organización Panamericana de la Salud-ops, 2008.

Programa Estado de la Nación. "Primer Informe Estado de la Nación en Desarrollo Humano Sostenible". San José, Costa Rica: Proyecto Estado de la Nación, 1994.

Programa Estado de la Nación. Aportes para el análisis de las brechas de equidad entre los géneros. Insumos para su medición. San José, Costa Rica, 2002.

Programa Estado de la Nación. Undécimo Informe Estado de la Nación. Aporte especial. "Brechas de equidad entre los géneros: acumulación de retos". San José, Costa Rica, 2005.

Programa Estado de Nación. Política Nacional para la igual y equidad de género. San José, Costa Rica, 2007.

Sen, Amartya. Desarrollo como libertad. Madrid, España: Editorial Planeta, 2000.

Sen, Amartya. Development as freedom. Reino Unido: Oxford University Press, 2001.

Sen, Amartya. Inequality reexamined. Reino Unido: Oxford University PressClarendon Press, 1992.

Sen, Amartya. Nuevo examen de la desigualdad. Madrid, España: Alianza Editorial sa, 1995.

Sojo, Carlos. Igualiticos: la construcción social de la desigualdad en Costa Rica. $1^{\mathrm{a}}$. ed. San José, Costa Rica: Programa de las Naciones Unidas para el Desarroll-pnud, 2010.

Taylor, Charles. Multiculturalism: examining the politics of recognition. New Jeresy, Eeuv: Princeton University Press, 1994.

Trejos, Juan Diego. La mujer microempresaria en Costa Rica: años 90. Proyecto de apoyo a programas de microempresa, Organización Internacional del Trabajo (orr). San José, Costa Rica: Instituto Nacional de las Mujeres, 2000.

Young, Iris. Justice and the politics of difference. New Jersey, Eevu: Princeton University Press, 1990.

\section{PUBLICACIONES PERIÓDICAS}

Fraser, Nancy. "After the family wage: Gender equity and the welfare state". Political theory 4 (22). eeuu. Sage Publications, 1994 591-618.

Fraser, Nancy. "Rethinking recognition". New Left Review. London, Inglaterra. 2000: 107-120.

Fraser, Nancy; Dahl, Hanne Marlene; Stoltz, Pauline y Willig, Rasmus. "Recognition, 
redistribution and representation in capitalist global society: an interview with Nancy Fraser". Acta Sociologica 4 (47). New York, eeuu. Sage Publications, 2004: 374-382.

Heidegren, Carl-Göran. "Recognition and social theory".Acta Sociologica 4 (47). New York, eEuu. Sage Publications, 2004: 365-373.

Hicks, Douglas. "Gender, discrimination, capability: insights from Amartya Sen". The Journal of Religious Ethics. New Jersey, eEuu, Wiley, 2002: 137-154.

Kabeer, Naila. "Gender equality and women's empowerment: a critical analysis of the third millennium development goal". Gender and Development 1 (13). Oxford, Reino Unido. Oxfam, marzo 2005: 13-24.

Martínez, Máriam. "Frágiles identidades e injusticias sociales: política de la diferencia en democracias complejas". Papeles 104. Madrid, España. 2008-2009: 11-20.

Nussbaum, Martha. "Capabilities and Social Justice". International Studies Review 2 (4). New Jersey, Eeuu. Wiley, 2002: 123135.

Rangel, Marta y Bello, Álvaro (consult.). "Comisión Económica para América Latina y el Caribe (CEPAL). La equidad y la exclusión de los pueblos indígenas y afrodescendientes en América Latina y el Caribe". Revista de la CEPAL 76. Santiago, Chile. Comisión Económica para América Latina y el Caribe de las Naciones Unidas, 2002.

Sen, Amartya. "Democracy as a universal value". Journal of Democracy 3 (10). Maryland, eeuu. Johns Hopkins University Press, 1999: 3-17.

Trejos, Juan Diego. El sector informal en Costa Rica a inicios del siglo XXI. San José, Costa Rica: Fundación Acceso y Women in Informal Employment Globalizing and Organizing-wIEGo, 2003.

Young, Iris. "Gender as seriality: thinking about women as a social collective". Signs 3
(19). Chicago, eeuu. The University of Chicago Press, 1994: 713-738.

\section{TEXTOS ELECTRÓNICO}

Instituto Interamericano de Derechos Humanos-IIDH. "Herramientas básicas para integrar la perspectiva de género en organizaciones que trabajan derechos humanos". Curso autoformativo [en línea]. San José, Costa Rica: Instituto Interamericano de Derechos Humanos, 2005. En: <http://www.iidh.ed.cr/> [consultado el 21 de agosto de 2012].

Ministerio de Trabajo y Seguridad Social. "Condiciones laborales de las mujeres en Costa Rica". Unidad de Equidad de Género. San José, Costa Rica, 2011. En $<$ http://www.mtss.go.cr/> [consultado el 15 de junio de 2011].

Tribunal Supremo de Elecciones. Política institucional para la igualdad y equidad de género. San José, Costa Rica. 2008. En: <http://www.tse.go.cr/pdf/normativa/ igualdadyequidaddegenero.pdf $>$ [consultado el 13 de septiembre de 2012].

OTROS

Goldenberg, Olga. "Indicadores de género para el seguimiento y la evaluación de la Plataforma de Acción de Beijing. Propuesta cepal. Indicadores no cuantitativos". Informe. San José, Costa Rica: Instituto Nacional de las MujeresProyecto Estado de la Nación-Programa Naciones Unidas para el Desarrollo, 2001. Goldemberg, Olga. "Brechas de equidad entre los géneros". Duodécimo Informe Estado de la Nación. San José, Costa Rica. 2006.

Programa de Desarrollo de las Naciones Unidas-PNud. Informe sobre Desarrollo Humano. New York, eeuu: Programa de Desarrollo de las Naciones Unidas. 2005

Fecha de ingreso: 26/09/2013 Fecha de aprobación: 18/12/13 
